\title{
Adsorção do dietil ftalato (DEP) em carvão ativado (CA) de casca de coco verde: caracterização físico-química e influência dos parâmetros operacionais
}

\author{
Adsorption of diethyl phthalate (DEP) on activated carbon (AC) from green coconut shell: \\ physical-chemical characterization and influence of operational parameters \\ Adsorción de ftalato de dietilo (DEP) sobre carbono activado (CA) de la cáscara de coco verde: \\ caracterización físico-química e influencia de los parámetros operativos
}

\section{Resumo}

A caracterização físico-química do CA na eliminação de DEP em efluente sintético foi estudada. Através das cinéticas e isotermas de adsorção, conforme delineamento fatorial de 11 ensaios e modelos matemáticos, verificou-se a influência da temperatura, pH, massa do CA. CA apresentou baixa área superficial $\left(554,228 \mathrm{~m}^{2} \mathrm{~g}^{-1}\right)$, área microporosa $\left(460,0539 \mathrm{~m}^{2} \mathrm{~g}^{-1}\right)$ e volume microporoso elevado $\left(0,253081 \mathrm{~cm}^{3} \mathrm{~g}^{-1}\right)$ pelo método de BET e BJH, e devido a ativação, elevada basicidade, $\mathrm{pH}_{\mathrm{PZC}}(7,2)$. A análise elementar e dos grupos funcionais da superfície pelo método de Boehm revelaram predominância de grupos básicos $\left(0,845 \mathrm{meq}^{-1}\right)$, lactonas $\left(0,211 \mathrm{meq}^{-1}\right)$ e fenóis $\left(0,169 \mathrm{meq}^{-1}\right)$, confirmado na espectroscopia no infravermelho (IRTF) pela presença de grupamentos quinona, lactona e carbonila. $\mathrm{O}$ tratamento de adsorção apresentou superiores coeficientes de determinação $\left(\mathrm{R}^{2}>0,90\right)$ no estudo das cinéticas para o modelo de pseudo-segunda ordem, e das isotermas, para o de Freundlinch. O CA apresentou, 83,5\% de taxa de eliminação de DEP, uma capacidade de adsorção de DEP de 27,006 $\mathrm{mg} \mathrm{g}^{-1} \mathrm{em} \mathrm{pH} \mathrm{7,}$ com $0,4 \mathrm{~g}$ de $\mathrm{CA}$ a $30^{\circ} \mathrm{C}$ em 360 minutos, entretanto, reduziu em $13 \%$ a sua taxa e $20,598 \mathrm{mg} \mathrm{g}^{-1}$ de capacidade de adsorção em pH 11, com $0,2 \mathrm{~g}$ de CA a $15^{\circ} \mathrm{C}$ em 360 minutos. Para a capacidade de adsorção e taxa de eliminaçao de DEP não ocorreu diferença significativa nos tratamentos com $(\mathrm{p}<0,5)$. Na Análise Termogravimétrica (ATG), a decomposição próximo a $600^{\circ} \mathrm{C}$, e pela Microscopia Eletrônica de Varredura (MEV), as propriedades texturais foram mantidas.

Palavras-chave: Efluente; Dietil ftalato; Carvão ativado; Catalisador; Capacidade de adsorção.

\begin{abstract}
The physicochemical characterization of AC in the elimination of DEP in synthetic effluent was studied. Through the adsorption kinetics and isotherms, according to the factorial design of 11 tests and mathematical models, the influence of temperature, $\mathrm{pH}$, and CA mass was verified. AC presented low surface area $\left(554.228 \mathrm{~m}^{2} \mathrm{~g}^{-1}\right)$, microporous area $\left(460.0539 \mathrm{~m}^{2} \mathrm{~g}^{-1}\right)$ and high microporous volume $\left(0.253081 \mathrm{~cm}^{3} \mathrm{~g}^{-1}\right)$ by the BET and BJH method, and due to activation, high basicity, $\mathrm{pH}_{\mathrm{PZC}}$ (7.2). Elemental and surface group analysis by the Boehm method revealed a predominance of basic groups $\left(0.845 \mathrm{meq}^{-1}\right)$, lactones $\left(0.211 \mathrm{meq}^{-1}\right)$ and phenols $\left(0.169 \mathrm{meq} \mathrm{g}^{-1}\right)$, confirmed by infrared spectroscopy (FTIR ) by the presence of quinone, lactone and carbonyl groups. The adsorption treatment presented higher coefficients of determination $\left(\mathrm{R}^{2}>0.90\right)$ in the study of kinetics for the pseudo-second order model, and of isotherms for the Freundlinch model. AC presented an 83.5\% DEP elimination rate, a DEP adsorption capacity of $27.006 \mathrm{mg} \mathrm{g}^{-1}$ at $\mathrm{pH} 7$, with $0.4 \mathrm{~g}$ of $\mathrm{AC}$ at $30^{\circ} \mathrm{C}$ in 360 minutes, however, it reduced by $13 \%$ its rate and $20.598 \mathrm{mg}$ $\mathrm{g}^{-1}$ of adsorption capacity at $\mathrm{pH} 11$, with $0.2 \mathrm{~g}$ of $\mathrm{AC}$ at $15^{\circ} \mathrm{C}$ in 360 minutes. For the adsorption capacity and DEP
\end{abstract}


elimination rate there was no significant difference in treatments with $(\mathrm{p}<0.5)$. In the Thermogravimetric Analysis (TGA), the decomposition close to $600^{\circ} \mathrm{C}$, and by Scanning Electron Microscopy (SEM), the textural properties were maintained.

Keywords: Effluent; Diethyl phthalate; Activated carbon; Catalyst; Adsorption capacity.

\section{Resumen}

Se estudió la caracterización fisicoquímica de CA en la eliminación de DEP en efluentes sintéticos. A través de la cinética de adsorción y las isotermas, de acuerdo con el diseño factorial de 11 pruebas y modelos matemáticos, se verificó la influencia de la temperatura, el $\mathrm{pH}$ y la masa de CA. CA presentó baja área superficial $\left(554,228 \mathrm{~m}^{2} \mathrm{~g}^{-1}\right)$, área microporosa $\left(460.0539 \mathrm{~m}^{2} \mathrm{~g}^{-1}\right)$ y alto volumen microporoso $\left(0.253081 \mathrm{~cm}^{3} \mathrm{~g}^{-1}\right)$ por el método BET y BJH, y debido a la activación, alta basicidad, $\mathrm{pH}_{\mathrm{PZC}}(7,2)$. El análisis elemental y los grupos funcionales superficiales por el método de Boehm reveló un predominio de grupos básicos $\left(0,845 \mathrm{meq} \mathrm{g}^{-1}\right)$, lactonas $\left(0,211 \mathrm{meq} \mathrm{g}^{-1}\right)$ y fenoles $(0,169$ meq $\mathrm{g}^{-1}$ ), confirmado por espectroscopia infrarroja (FTIR) por la presencia de grupos quinona, lactona y carbonilo. El tratamiento de adsorción presentó mayores coeficientes de determinación $\left(\mathrm{R}^{2}>0.90\right)$ en el estudio de cinética para el modelo de pseudo-segundo orden, y de isotermas para el modelo de Freundlinch. CA presentó una tasa de eliminación de DEP de $83.5 \%$, una capacidad de adsorción de DEP de $27.006 \mathrm{mg} \mathrm{g}^{-1}$ a pH 7, con $0.4 \mathrm{~g}$ de CA a $30^{\circ} \mathrm{C}$ en 360 minutos, sin embargo, redujo en $13 \%$ su tasa y $20.598 \mathrm{mg} \mathrm{g}^{-1}$ de capacidad de adsorción a pH 11, con $0,2 \mathrm{~g}$ de CA a $15^{\circ} \mathrm{C}$ en 360 minutos. Para la capacidad de adsorción de DEP y la tasa de eliminación no hubo diferencias significativas en los tratamientos con $(\mathrm{p}<0.5)$. En el Análisis Termogravimétrico (ATG), la descomposición cercana a $600^{\circ} \mathrm{C}$, y por Microscopía Electrónica de Barrido (MEB), se mantuvieron las propiedades texturales.

Palabras clave: Efluente; Ftalato de dietilo; Carbón activado; Catalizador; Capacidad de adsorción.

\section{Introdução}

A poluição química de natureza orgânica é um dos principais problemas ambientais decorrentes dos despejos industriais e domésticos. Devido ao impacto negativo ao meio ambiente existe, então, uma crescente imposição dos órgãos regulamentadores ambientais, principalmente na Europa para minimizar a emissão de poluentes orgânicos emergentes (POEs) pelas industriais, como estratégia de tratamento de efluentes agroindustriais, sobretudo, pela redução dos efluentes lançados aos corpos receptores sem tratamento eficiente.

O carvão ativado (CA) é frequentemente utilizado como adsorvente para remover contaminantes orgânicos. Materiais que possuem um alto teor de carbono, como madeira, hulha, lignina, casca de coco, bambu, quitosana, podem ser convertidos em CA, assim como rejeitos do café (Ramos et al., 2009), casca de noz (Fang \& Huang, 2009), serragem (Bajpai et al., 2012). A quantidade de adsorvato que pode ser adsorvido por um adsorvente é em função tanto das características como da concentração de adsorvato e características de fase líquida tais como: pH e temperatura (Chaudhary et al., 2003; Fu et al., 2015). Seu poder adsorvente é proveniente da alta área superficial e da presença de uma variedade de grupos funcionais em sua superfície (Guilarduci et al., 2006; Barbosa et al., 2014).

A produção de CA envolve duas etapas: a carbonização do precursor em atmosfera inerte e a ativação do material carbonizado (Wigmans, 1989; Rocha et al., 2006). Os carvões podem ser ativados por processos físicos (Moreno-Castilha et al., 2001), químicos (Ramos et al., 2009). Deste modo, CA pode ser uma alternativa de reaproveitamento sustentável da casca do coco verde.

Dentre os POEs, a União Europeia (EU), como medida preventiva, classificou os fltalatos como substâncias perigosas prioritárias e determinou a redução de $30 \%$ até 2020, destes micropoluentes, nos efluentes industriais aquosos com a concentração de ftalatos permitida de $1,3 \mu \mathrm{g} \mathrm{L} \mathrm{L}^{-1}$ nos corpos de água (Oliveira, 2011a). Deste modo, dentre os ésteres de ftalato (PAEs), o dietil ftlato (DEP) foi a substância escolhida para investigação do processo de adsorção como tratamento para eliminação de DEP de efluente sintético. Os ftalatos podem promover impactos adversos na saúde do homem por interferir no funcionamento normal do sistema endócrino (Kim, 2007; Abdelmelek, 2011) e do sistema reprodutivo, por sua ação cancerígena e mutagênica. Os autores GaniI \& Kazmi (2016) fornecem uma revisão crítica do nível de contaminação de ftalatos no ambiente aquático incluindo superfície, terra, e água potável e o nível de contaminação mais elevado é nas águas 
residuais, seguido pelas águas superficiais, subterrâneas e água potável. A principal fonte de contaminação por ftalatos em fontes aquáticas ocorre em lançamentos de efluentes após tratamento e ainda carregados de ftalatos. Para DEP os regulamentos e valores toxicológicos, conforme as Normas de Qualidade Ambiental (NQA) (NET et al., 2015) e a concentração letal (CL) para organismos aquáticos (Call et al., 2001), são $200 \mu \mathrm{g} \mathrm{L}^{-1}$ (NQA) e 4,21-102 $\mathrm{mg} \mathrm{L}^{-1}$ (CL).

Neste contexto, o objetivo deste estudo foi determinar a eficiência do processo de adsorção de DEP pelo CA, quanto a capacidade de adsorção, taxa de eliminação do micropoluente, assim como o tempo de equilíbrio. Utilizou-se um delineamento fatorial de onze ensaios com três variáveis independentes (massa do $\mathrm{CA}, \mathrm{pH}$, temperatura) para determinação de variáveis com diferença estatística significativa $(\mathrm{p}<0,05)$.

\section{Metodologia}

\subsection{Amostra de CA}

O carvão ativado (CA) de casca de coco verde foi doado pela empresa FBC Fábrica Brasiliera de Catalisadores, Brasil. Foi lavado até alcançar o pH neutro, antes da determinação das funções de superfície. Uma massa de 4,0 g CA foi introduzida em $2 \mathrm{~L}$ de água destilada sob agitação a $7 \mathrm{rpm}$ durante $1 \mathrm{~h}$. Procedeu-se a filtração em papel de filtro após cada lavagem, para em seguida aferir o pH da solução (Oliveira et al., 2011a; 2011b).

\subsection{Determinação das funções de superfície do CA: Método de Boehm}

A identificação e quantificação das funções químicas da superfície do CA foi determinada por titulação acidimétrica de acordo com a metodologia proposta por Boehm (Boehm et al., 1964, Boehm, 2002; Oickle et al., 2010).

Um volume de $25 \mathrm{~mL}$ de solução de $\mathrm{NaHCO}_{3}, \mathrm{Na}_{2} \mathrm{CO}_{3}, \mathrm{NaOH}$ e $\mathrm{HCl}\left(0,02 \mathrm{~mol} \mathrm{~L}^{-1}\right)$ foi introduzido em reatores, frascos de Erlenmeyer, uma massa de $200 \mathrm{mg}$ de CA e mantidos sob agitação de $150 \mathrm{rpm}$ por 48 horas usando um shaker (Tecnal, modelo TE424), a uma temperatura de $25^{\circ} \mathrm{C}$. Depois de 48 horas de agitação, o conteúdo destes reatores seguiu uma filtração simples com membranas a $0,45 \mu \mathrm{m}$. Todas as análises foram realizadas em triplicata. As funções ácido foram determinadas utilizando soluções de $\mathrm{NaHCO}_{3}, \mathrm{Na}_{2} \mathrm{CO}_{3}$ e $\mathrm{NaOH}\left(0,02 \mathrm{~mol} \mathrm{~L}^{-1}\right)$ em excesso e foram tituladas com uma solução de $\mathrm{HCl}\left(0,02 \mathrm{~mol} \mathrm{~L}^{-1}\right)$ (Oliveira et al., 2011a; 2011b; Flouret et al., 2018).

\subsection{Determinação do $\mathrm{pH}$ no ponto de carga zero (pHpzc)}

$\mathrm{O}$ pH $\mathrm{PZC}$ foi determinado por metodologia proposta por Faria et al. (2004) e Pereira et al. (2007). Um volume de 50 $\mathrm{mL}$ de solução de $\mathrm{NaCl}\left(0,01 \mathrm{~mol} \mathrm{~L}^{-1}\right)$ foi introduzido em cada reator, frasco de Erlenmeyer de $250 \mathrm{~mL}$, contendo $0,15 \mathrm{~g}$ de $\mathrm{CA}$, e o pH de cada reator foi ajustado (em valores entre 2 e 12) por adição de uma solução de $\mathrm{NaOH}$ ou de $\mathrm{HCl}\left(0,1 \mathrm{~mol} \mathrm{~L}^{-1}\right)$. A manutenção da agitação de $150 \mathrm{rpm}$ deu-se durante 48 horas, utilizando um shaker (Tecnal, modelo TE424), a uma temperatura de $25^{\circ} \mathrm{C}$. Seguiu-se filtração simples com membrana a $0,45 \mu \mathrm{m}$ de poro. Mediu-se então o pH final de cada

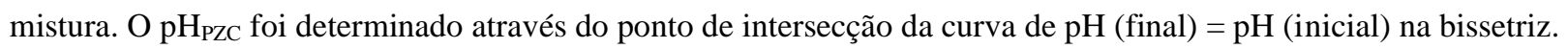

\subsection{Espectroscopia no Infravermelho da Transformada de Fourier (IRTF)}

O CA foi analisado por espectroscopia na região do infravermelho com transformada de Fourier (IRTF), para identificação de grupos isolados em espectrômetro (PerkinElmer, modelo Spectrum 400), com faixa espectral na região de 400 a $4000 \mathrm{~cm}^{-1}$. Os grupamentos superficiais que têm momentos de dipolo intenso dão origem, em geral, a absorções intensas no infravermelho (Silverstein et al., 2007). Aplicou-se a metodologia proposta por Cagnon et al. (2005) e Ishizak et al. (1981). 


\subsection{Análise elementar (CHN)}

As amostras foram analisadas quanto aos teores de C, H, N, em um aparelho marca Thermo Scientific Flash 2000, segundo a norma ASTM D 5373 (2008), para altos valores de carbono em carvão (35 - 80\%) e para baixos teores de carbono em cinzas (1 - 10\%) e o teor de oxigênio foi obtido por diferença (Truspec CHN/CHNS, 2007; Fallavena et al., 2013).

\subsection{Análise de área superficial (BET), distribuição dos poros (método BJH)}

As isotermas de adsorção e dessorção de $\mathrm{N}_{2}$ foram realizadas a $77 \mathrm{~K}$ em um equipamento de alta pressão marca Asap 2020, utilizando o programa Micromeritics. Com uso de um porosímetro de mercúrio marca Autopore IV 9500, Micromeritics Instrument Corp, modelo Gemini V1.00 Serial 3245. A amostra foi previamente tratada a $250^{\circ} \mathrm{C}$ por $12 \mathrm{~h}$. A distribuição de tamanhos de poros foi calculada a partir da isoterma de adsorção de $\mathrm{N}_{2}$ usando o método BJH. A área superficial específica foi calculada utilizando a equação BET na região de baixa pressão $\left(\mathrm{p} / \mathrm{p}_{0}=0,200\right)$. Através da ampla faixa de medição e porosimetria de mércurio, pode-se calcular inúmeras propriedades de amostra, tais como distribuições de tamanho de poro, volume total de poros, a área total dos poros da superfície, diâmetro médio dos poros, e densidades de amostra (a granel e esqueléticas). O tamanho de poro está disponível a partir de 8,5 a 1.500,000 Å. A caracterização estrutural foi realizada em CA a partir da aplicação de várias expressões matemáticas (teoria Dubinin - Radushkevich, método alfa, método BET, método BJH), caracterizando o material conforme as pesquisas de Juszczak et al. (2002) e Santana et al. (2012).

\subsection{Cinéticas de adsorção}

As cinéticas de adsorção foram investigadas para verificar a eficiência do processo de adsorção pela determinação da capacidade de adsorção de CA para DEP, da taxa de eliminação de DEP (\%) e do tempo de equilíbrio (minutos). Foi realizado um planejamento fatorial de acordo com a Tabela 1. As condições experimentais foram aplicadas em um reator, frasco de Erlenmeyer com $250 \mathrm{~mL}$ do efluente sintético, a uma concentração do micropoluente de $0,2 \mathrm{~g} \mathrm{~L}^{-1}$, escolhida como padrão. $\mathrm{O}$ reator foi colocado em equipamento shaker marca Tecnal, modelo TE424, com controle de agitação fixada em $150 \mathrm{rpm}$. Durante os processos de adsorção, amostras foram coletadas em diferentes intervalos de tempos $(0,5,10,15,25,35,45,60$, $80,100,120,150,180,210,240,360,1380,1440$ minutos) com o objetivo de avaliar a eliminação do poluente na solução (Oliveira et al., 2011a; 2011b; Flouret et al., 2018). As análises da concentração do DEP de todos os processos estudados foram aferidas por espectrometria UV marca Femto Espectrofotômetro 700 Plus a $228 \mathrm{~nm}$ (comprimento de onda de DEP). A curva de calibração de solução de dietil ftlato (DEP) foi feita entre 0,025 e $0,2 \mathrm{~g} \mathrm{~L}^{-1}$. A capacidade de adsorção (mg g $\left.\mathrm{g}^{-1}\right)$ do carvão ativado foi então calculada pela Equação 1; e a taxa de eliminação do DEP (\%), foi calculada pela Equação 2.

$$
q_{t}=\frac{\left(C_{o}-C_{t}\right) \cdot V}{m}
$$

Em que: $\mathrm{q}_{\mathrm{t}}=$ capacidade de adsorção de $\mathrm{CA}\left(\mathrm{mg} \mathrm{g}^{-1}\right) ; \mathrm{C}_{\mathrm{o}}$ e $\mathrm{C}_{\mathrm{t}}=$ concentrações do poluente $\left(\mathrm{g} \mathrm{L}^{-1}\right)$, respectivamente no estado inicial e no instante $\mathrm{t}(\mathrm{min}) ; \mathrm{V}=$ volume da solução (L); $\mathrm{m}=$ a massa do carvão ativado (g).

$$
t a_{t}=\frac{[D E P]_{0}-[D E P]_{t}}{[D E P]_{0}} .100
$$

(Equação 2).

Em que: $[D E P]_{0}$ e $[D E P]_{t}=$ as concentrações de dietil ftalato (DEP), respectivamente, nos instantes inicial e no instante $t\left(\mathrm{~g} \mathrm{~L}^{-1}\right) ; \mathrm{ta}_{\mathrm{t}}=$ taxa de eliminação de $\operatorname{DEP}(\%)$. 
Tabela 1. Valores aplicados no planejamento fatorial para três variáveis independentes.

\begin{tabular}{lccc}
\hline Cinéticas & Massa de CA $(\mathbf{g})$ & $\mathbf{p H}$ & Temperatura $\left({ }^{\circ} \mathbf{C}\right)$ \\
\hline 1 & 0,2 & 3,0 & 15,0 \\
2 & 0,6 & 3,0 & 15,0 \\
3 & 0,2 & 11,0 & 15,0 \\
4 & 0,6 & 11,0 & 15,0 \\
5 & 0,2 & 3,0 & 45,0 \\
6 & 0,6 & 3,0 & 45,0 \\
7 & 0,2 & 11,0 & 45,0 \\
8 & 0,6 & 11,0 & 45,0 \\
9 & 0,4 & 7,0 & 30,0 \\
10 & 0,4 & 7,0 & 30,0 \\
11 & 0,4 & 7,0 & 30,0 \\
\hline
\end{tabular}

Fonte: Adaptação de Rodrigues e Iemma (2009).

\subsubsection{Modelagem matemática das cinéticas de adsorção}

As cinéticas de adsorção são usualmente descritas pelos modelos de pseudo- primeira-ordem (Lagergren, 1898), de pseudo-segunda-ordem (Ho et al., 1996), e de difusão intrapartícula (Weber et al., 1963) para a maioria dos sistemas adsorvente-adsorbato (Bertolini \& Fungaro, 2011), cujas equações estão descritas na Tabela 2. Foi utilizado programa Statistica 7.0 (StatSoft Inc., Tulsa, Oklahoma, EUA), pela regressão não linear dos dados. O critério de escolha dos melhores ajustes se baseou na determinação do coeficiente de determinação $\left(\mathrm{R}^{2}\right)$.

Tabela 2. Modelos matemáticos aplicados às cinéticas de adsorção do CA.

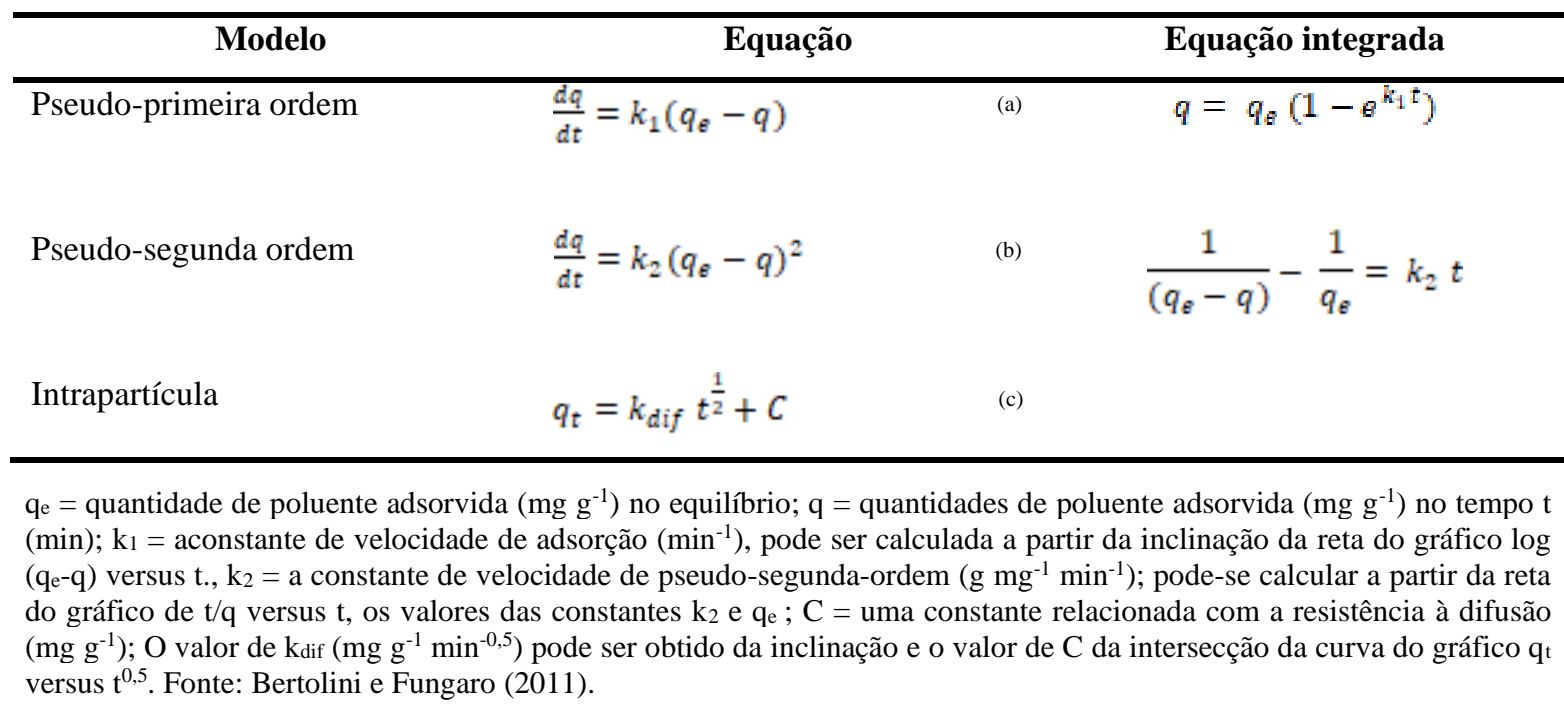

\subsection{Isotermas de adsorção}

As isotermas de adsorção foram realizadas de acordo com as condições de tratamento do efluente sintético por adsorção de DEP por CA, conforme as cinéticas de adsorção $\mathrm{C} 9$ (pH 7, 0,4 g de CA, 30 ${ }^{\circ} \mathrm{C}$ ), $\mathrm{C} 8$ (pH 11, 0,6 g de CA, 45 $\mathrm{C}$ ), $\mathrm{C6}$ ( $\mathrm{pH} 3,0,6 \mathrm{~g}$ de $\left.\mathrm{CA}, 45^{\circ} \mathrm{C}\right), \mathrm{C} 8$ e $\mathrm{C} 6$ (Tabela 1). Estas condições experimentais apresentaram, respectivamente, maior, intermediária e menores capacidades de adsorção. Aplicou-se o seguinte procedimento: as massas de CA foram adicionadas a oito soluções de DEP com concentrações diferentes: 0,025;0,05;0,075;0,1;0,125;0,15;0,175 e 0,2 g L $\mathrm{L}^{-1}$; tais soluções de 
DEP, cada uma das concentrações em um reator, frasco de Erlenmeyer com $250 \mathrm{~mL}$ de efluente sintético, sob temperaturas de acordo com cada condição experimental e agitação de 150 rpm monitoradas, em shaker marca Tecnal, modelo TE424. As amostras foram coletadas nos tempos zero $\left(\mathrm{t}_{0}\right)$ e nos respectivos tempos de equilíbrio $\left(\mathrm{t}_{\mathrm{eq}}\right.$ ) definidos no estudo cinético em 360 , 120 e 1260 minutos, respectivamente para C9, C8 e C6. As amostras obtidas foram filtradas por filtração simples em membrana de 0,45 $\mu \mathrm{m}$ e analisadas por espectrometria de UV (228 nm) da marca Femto Espectrofotômetro 700 Plus. Calculou-se a capacidade de adsorção no equilíbrio $\mathrm{q}_{\mathrm{eq}}\left(\mathrm{mg} \mathrm{g}^{-1}\right)$ utilizando a Equação 1 (Flouret et al., 2018; Almeida et al, 2020).

\subsubsection{Modelagem matemática das isotermas de adsorção}

As isotermas foram ajustadas aos modelos de isotermas de Langmuir e de Freundlich de acordo com a Tabela 3. Estes são representados por equações simples que relacionam diretamente o volume adsorvido em função da pressão e/ou concentração do adsorvato. São comumente utilizados por muitos autores no estudo de adsorção (Benkhedda et al., 2000; Asheh et al., 2003; Kumar et al., 2003; Hocine et al., 2004; Aksu \& Lyubchik et al., 2004; Witthuhn et al., 2005; Freitas, 2005).

Tabela 3. Modelos matemáticos aplicados às isotermas de adsorção do CA.

\begin{tabular}{|c|c|c|}
\hline Modelo & Equação & \\
\hline Langmuir & $q_{e}=q_{m L}\left(\frac{b c_{g}}{1+b c_{g}}\right)$ & (a) \\
\hline Freundlinch & $q_{e}=k_{F} C_{e}^{\frac{1}{n_{F}}}$ & (b) \\
\hline
\end{tabular}

\subsection{Análise termogravimétrica (ATG)}

As análises de CA pré e pós-cinéticas de adsorção foram realizadas de acordo com a metodologia proposta por Ramos et al. (2009) em um analisador termomecânico marca Shimadzu, modelo DTG 60/60H, o fluxo de calor e a temperatura de decomposição de DEP no calorímetro DSC modelo 60 Plus. A amostras foram colocadas num forno a $80^{\circ} \mathrm{C}$ antes de cada análise de ATG durante 24 horas. A massa de 0,2 gramas de CA foi introduzida em cadinhos de platina com uma taxa de fluxo de $10 \mathrm{~L} \mathrm{~min}^{-1}$ de ar sintético até uma temperatura de $1200^{\circ} \mathrm{C}$. As amostras foram aquecidas a uma taxa de $10^{\circ} \mathrm{C} \mathrm{min}{ }^{-1}$.

\subsection{Microscopia eletrônica de varredura (MEV)}

As características morfológicas de CA foram realizadas de acordo com Zhang et al. (2014) em Microscópio Eletrônico de Varredura (MEV), marca Jeol, modelo JSM-6610, Tokio Japão, equipado com Espectrômetro de Dispersão de Energia (EDS), marca Thermo Scientific NSS Spectral Imaging. As imagens do MEV de CA foram tomadas a uma tensão de aceleração de $5 \mathrm{kV}$. O relativo elementar das composições de CA foram examinadas com EDS depois de serem revestidas com ouro na superfície.

\subsection{Análise estatística}

Os dados obtidos foram analisados com auxílio do programa Statistica 7.0 (StatSoft Inc., Tulsa, Oklahoma, EUA), com nível de significância $(\mathrm{p}<0,05)$, para determinar as superfícies de resposta. 


\section{Resultados e Discussão}

\subsection{Determinação das funções de superfície do CA: Método de Boehm e pHPZC}

Os resultados na Tabela 4 mostram que a quantificação de grupos ácidos e básicos funcionais da superfície do CA tem predominância de propriedade química básica, sendo os grupos funcionais de superfície de caráter equivalente básico (total ácido $=0,523$ meq $\mathrm{g}^{-1}$ e total básico $=0,845 \mathrm{meq} \mathrm{g}^{-1}$ ). No entanto, a natureza dos seus grupos ácidos são diferentes, 15,09\% ácido carboxílicos, 36,36\% fenólicos e 47,72\% lactonas, e a maioria dos grupos funcionais são grupos lactonas e fenol. Dabrowski et al. (2005) mostraram que os grupos carboxilícos e hidroxil aumentam a interação do CA com a água. A presença de grupos básicos (cromeno, pirona) é um fator-chave na promoção de adsorção irreversível (quimissorção).

Tabela 4. Quantificação dos grupos oxigenados da superfície de CA pelo método de Boehm.

\begin{tabular}{|c|c|c|c|c|c|c|}
\hline $\mathbf{C A}$ & $\begin{array}{c}\text { Carboxílicos } \\
\left(\text { meq g }^{-1}\right)\end{array}$ & $\begin{array}{l}\text { Fenólicos } \\
\left(\text { meq } \mathbf{g}^{-1}\right)\end{array}$ & 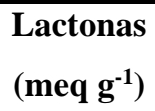 & $\begin{array}{c}\text { Total ácido } \\
\left(\text { meq g } \text { g }^{-1}\right)\end{array}$ & $\begin{array}{c}\text { Total básico } \\
\left(\text { meq g }^{-1}\right)\end{array}$ & Característica \\
\hline A & 0,071 & 0,169 & 0,211 & 0,523 & 0,845 & Básica \\
\hline
\end{tabular}

Fonte: Autores.

O pHPZC obtido para CA (Figura 1) é consistente com a quantificação de grupos funcionais da superfície obtido pelo método de Boehm com valor de $\mathrm{pH} 7,2$, ou seja, entre 7,1 e 7,5. Os valores determinados para pHPZC podem determinar que o caráter ácido ou básico do CA depende do pH da solução e da interação com a carga líquida da superfície do CA.

Figura 1. Curva de determinação do $\mathrm{pH}_{\mathrm{PZC}}$ aplicado ao $\mathrm{CA}$, $\mathrm{pH}$ Final versus $\mathrm{pH}$ Inicial.

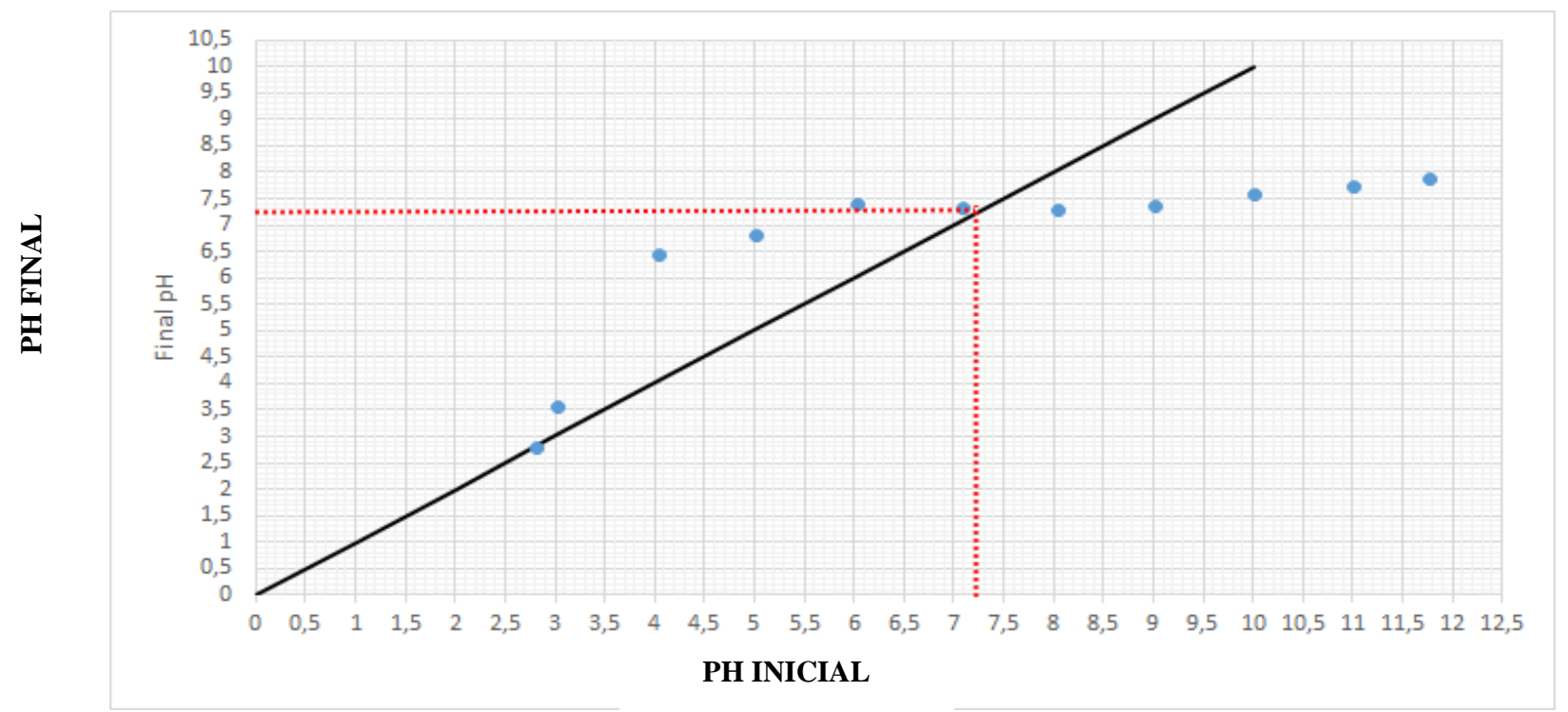

Fonte: Autores.

Além disso para adsorção, pode-se dizer que, para $\mathrm{pH}<\mathrm{pKA}$ (ácido fraco), o DEP ( $\mathrm{pHOH} / \mathrm{pHO}^{-}$) não depende da carga de superfície do CA. No entanto, para pH > pKA, o DEP é dissociado, e sua adsorção na forma iônica depende da carga de superfície. Assim, como o pKA é $(2,943)$ de DEP e o pH PZC do CA para um pH superior a 10, tanto a superfície do CA, como a carga de DEP são negativas, ocorre repulsão eletrostática e a adsorção não é favorecida. 


\subsection{Análise IRTF e Elementar}

Os resultados da análise de IRTF estão apresentados na Figura 2 e Tabela 5. O método IRTF permitiu uma estimativa qualitativa dos grupos funcionais, com maior absorção é entre 1500 e $1800 \mathrm{~cm}^{-1}$, que representam os grupos quinona, lactona e carbonila. Grandes quantidades de grupos oxigenados entre $1710 \mathrm{~cm}^{-1}$ e $1750 \mathrm{~cm}^{-1}$, ligação $\mathrm{C}=\mathrm{O}$, grupos ácido carboxílico, anidro e lactonas (Oliveira et al., 2011b). Entre 1100 e $1250 \mathrm{~cm}^{-1}$, a ligação C-O (1125: ácido anidro, 1175: fenol) e entre 1500 e $1800 \mathrm{~cm}^{-1}$ (carbonila e quinona). Na Figura 2, as letras (A), (B) e (C) representam, respectivamente, o comprimento de onda de adsorção para: (A) anidridos de ácido fenol; (B) ácido carboxílico, anidrido e lactona; e (C) grupos carbonila e de quinona. Deste modo, o IRTF revela a predominância de grupos carbonila e de quinona, grupos importantes para adsorção de DEP pelo CA. Absorção situada em $1749 \mathrm{~cm}^{-1}$ é característica de estiramento vibracional de $\mathrm{C}=\mathrm{O}$ de carbonila, que é vibração de deformação axial da ligação C-O, já a que aparece próximo a $1168 \mathrm{~cm}^{-1}$, sugere a presença tanto de ácidos carboxílicos como de ésteres ou $\delta$-lactonas ligados a grupos aromáticos (Guilarduci et al., 2006). As absorções em 1600 e $1480 \mathrm{~cm}^{-1}$ presentes em ambos os CAs são referentes ao estiramento $\mathrm{C}=\mathrm{C}$ de aromáticos (Ahmad et al., 2007).

Como CA é subproduto de agroindústria, onde a matéria-prima foi coco verde, a análise elementar apresentada na Tabela 5, revelou seu maior teor carbonáceo. No entanto, como o CA tem um elevado teor de carbono e um baixo teor de hidrogênio, nitrogênio e oxigênio, pode-se esperar que possua uma baixa quantidade de grupos funcionais. Estes resultados estão de acordo com estudos de determinação da capacidade de adsorção de CA(s) de rejeito de café por Ramos et al. (2009) e de serragem por Bajpai et al. (2012).

Figura 2. Espectro do CA plotado com valores de Absorbância (u.a.) x Comprimento de onda $\left(\mathrm{cm}^{-1}\right)$ determinados pelo método de IRTF.

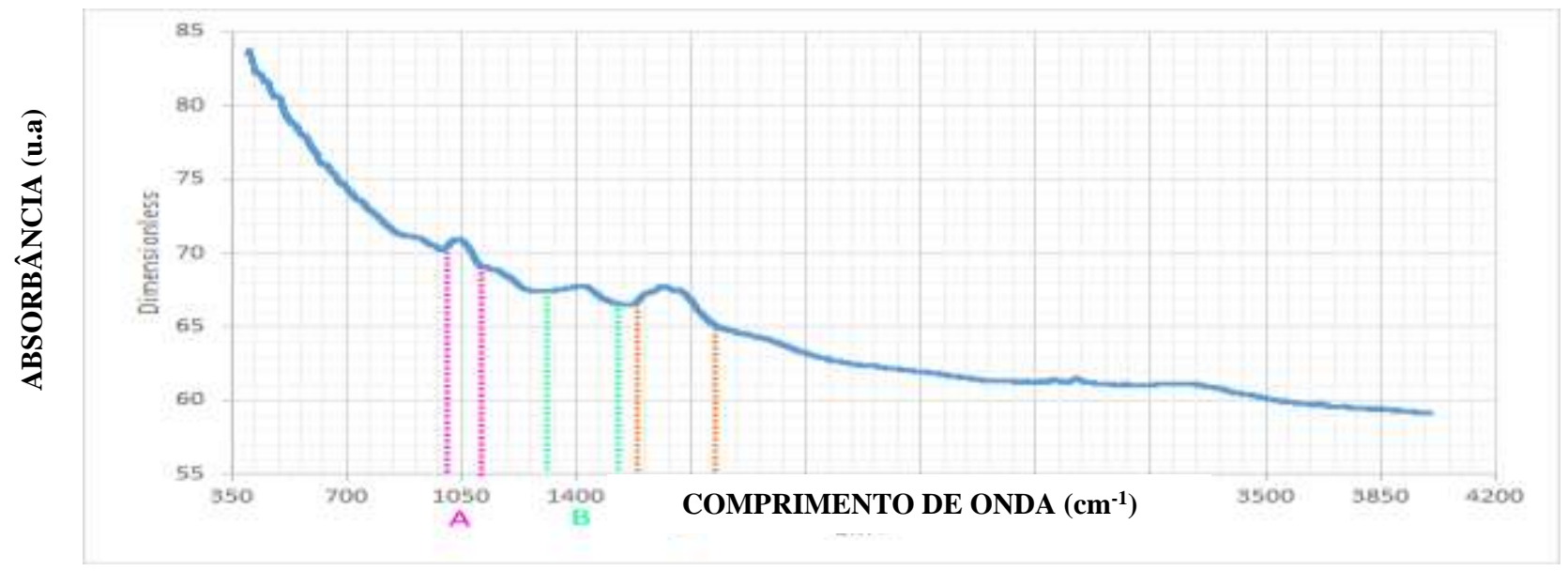

Fonte: Autores.

Tabela 5. Análise elementar de CA.

\begin{tabular}{llllll}
\hline Material & $\mathbf{C}(\boldsymbol{\%})$ & $\mathbf{H}(\boldsymbol{\%})$ & $\mathbf{N}(\boldsymbol{\%})$ & $\mathbf{O}(\boldsymbol{\%})$ & $\mathbf{C} / \mathbf{H}$ \\
\hline $\mathrm{CA}$ & 88,5 & 0,6 & 0,5 & 10,4 & 147,5 \\
\hline
\end{tabular}

Fonte: Autores.

\subsection{Análise das propriedades texturais de CA}

A isoterma de adsorção/desorção de $\mathrm{N}_{2}$ (Figura 3a), com coeficiente de determinação $\left(\mathrm{R}^{2}\right)$ de 0,993 indicou elevada adsorção a baixas pressões de $\mathrm{N}_{2}$, evidenciando a formação de microporos. A área superficial determinada pelo método BET 
( $\left.\mathrm{S}_{\mathrm{BET}}\right)$ foi de $554,228 \mathrm{~m}^{2} \mathrm{~g}^{-1} \mathrm{e}$ a análise da distribuição do volume de poros em função do raio pelo método de BJH indicou que o CA é principalmente constituído por microporos com raio de 0,160 a $0,263 \AA$ A . Os resultados das propriedades porosas de CA estão apresentadas na Tabela 6.

Figura 3. (a) Isoterma de adsorção e desorção de Nitrogênio $\left(\mathrm{N}_{2}\right)$ a $77 \mathrm{~K}$ do CA.

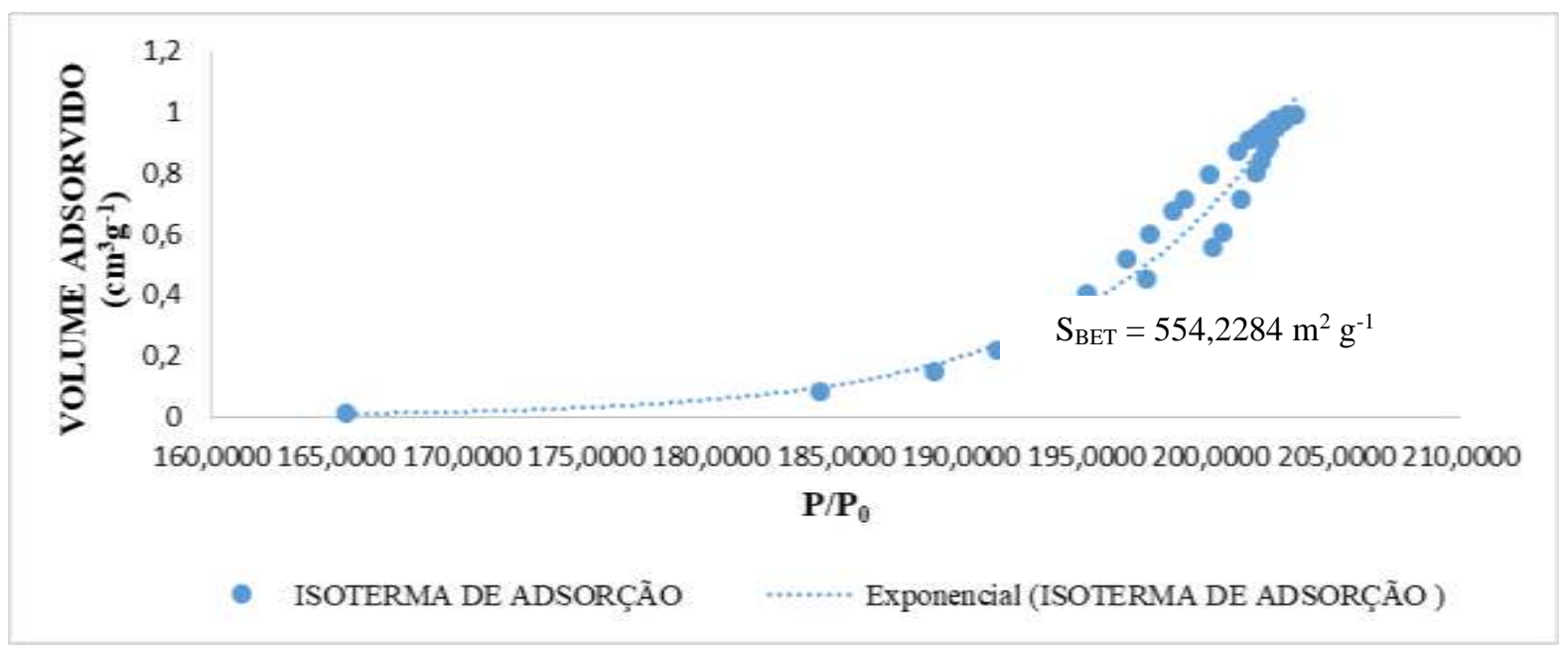

Fonte: Autores.

Tabela 6. Propriedades da área de superfície do CA pelo método de BET.

\begin{tabular}{cccccc}
\hline $\begin{array}{c}\text { Área single point } \\
(\mathbf{p} / \mathbf{0} \mathbf{0}=\mathbf{0 . 2 9}) \\
\left(\mathbf{m}^{\mathbf{2}} \mathbf{g}^{-1}\right)\end{array}$ & $\begin{array}{c}\mathbf{W}_{\mathbf{0}} \\
\left(\mathbf{c m}^{\mathbf{3}} \mathbf{g}^{-1}\right)\end{array}$ & $\begin{array}{c}\mathbf{L}_{\mathbf{0}} \\
(\mathbf{\AA})\end{array}$ & $\begin{array}{c}\mathbf{S}_{\text {ext }} \\
\left(\mathbf{m}^{2} \mathbf{g}^{-1}\right)\end{array}$ & $\begin{array}{c}\mathbf{S}_{\text {micro }} \\
\left(\mathbf{m}^{2} \mathbf{g}^{-1}\right)\end{array}$ & $\begin{array}{c}\mathbf{S}_{\text {total }} \\
\left(\mathbf{m}^{2} \mathbf{g}^{-1}\right)\end{array}$ \\
\hline 596,9458 & & & & & \\
\hline
\end{tabular}

Fonte: Autores.

Figura 3. (b) Volume acumulativo dos poros em função do tamanho do poro pelo método BJH.

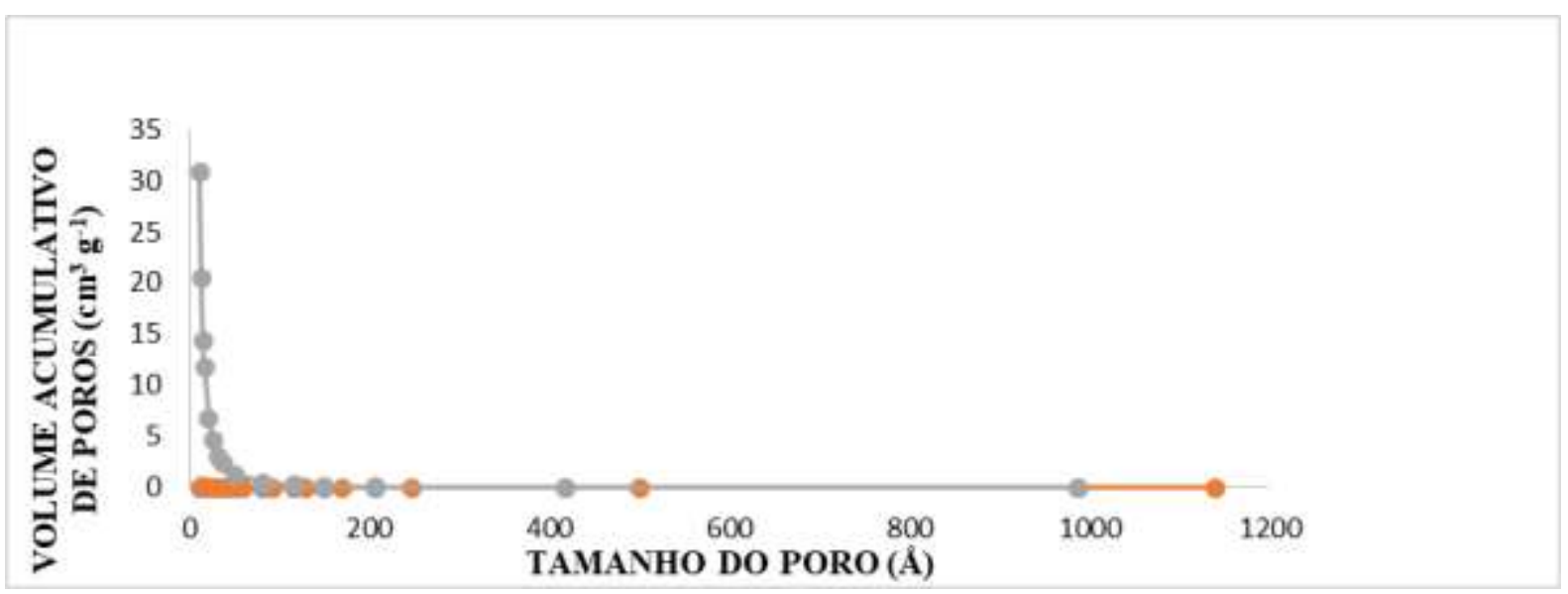

Fonte: Autores. 


\subsection{Cinéticas de adsorção}

As curvas das cinética de adsorção DEP foram obtidas através da representação gráfica da capacidade de adsorção de (mg g $\left.{ }^{-1}\right)$ em função do tempo (minutos). A Figura 4 ilustra as variações entre as cinéticas de adsorção de DEP por CA nas condições experimentais testadas. Pode-se observar que inicialmente o processo de adsorção é rápido, o que provavelmente está relacionado com os sítios de adsorção disponíveis na superfície do carvão, seguido de um processo mais lento (Tsang et al., 2007). Em seguida, então, o desenvolvimento do processo de adsorção atenua-se, até alcançar um patamar de estado estável, que ocorre quando o equilíbrio foi atingido.

Os resultados evidenciam que as maiores capacidade de adsorção de DEP e taxa de eliminação, e menor tempo de equilíbrio atingido foram na condição $\mathrm{C} 9,\left(\mathrm{pH} 7-0,4 \mathrm{~g} \mathrm{CA}-30^{\circ} \mathrm{C}\right), 27,007 \mathrm{mg} \mathrm{g}^{-1}, 83,5 \%$ após 360 minutos respectivamente. Pode-se verificar a repetitibilidade das respostas, para $\mathrm{C} 9, \mathrm{C} 10$ e $\mathrm{C} 11$, os pontos centrais do delineamento, com capacidades de adsorção de DEP e taxas de eliminação de DEP de 24,980 e 27,025 $\mathrm{mg} \mathrm{g}^{-1} ; 79,9$ e 80,3\%, para C10 e C11, respectivamente e tempos de equilíbrio de 360 minutos para ambas (Figura 5).

Figura 4. As capacidades de adsorção $\left(\mathrm{mg} \mathrm{g}^{-1}\right)$ em função do tempo (minutos) das cinéticas de adsorção em CA de DEP de C1

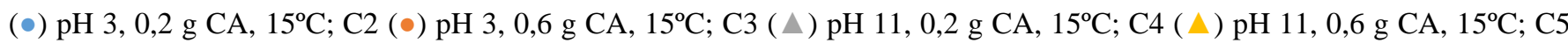

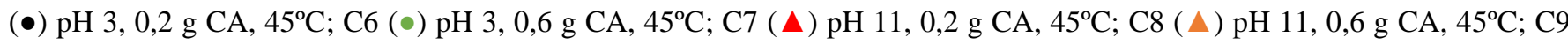
(घ) $\mathrm{pH} 7,0,4 \mathrm{~g} \mathrm{CA}, 30^{\circ} \mathrm{C} ; \mathrm{C} 10(\bullet) \mathrm{pH} 7,0,4 \mathrm{~g} \mathrm{CA}, 30^{\circ} \mathrm{C} ; \mathrm{C} 11$ (घ) $\mathrm{pH} 7,0,4 \mathrm{~g} \mathrm{CA}, 30^{\circ} \mathrm{C}$.

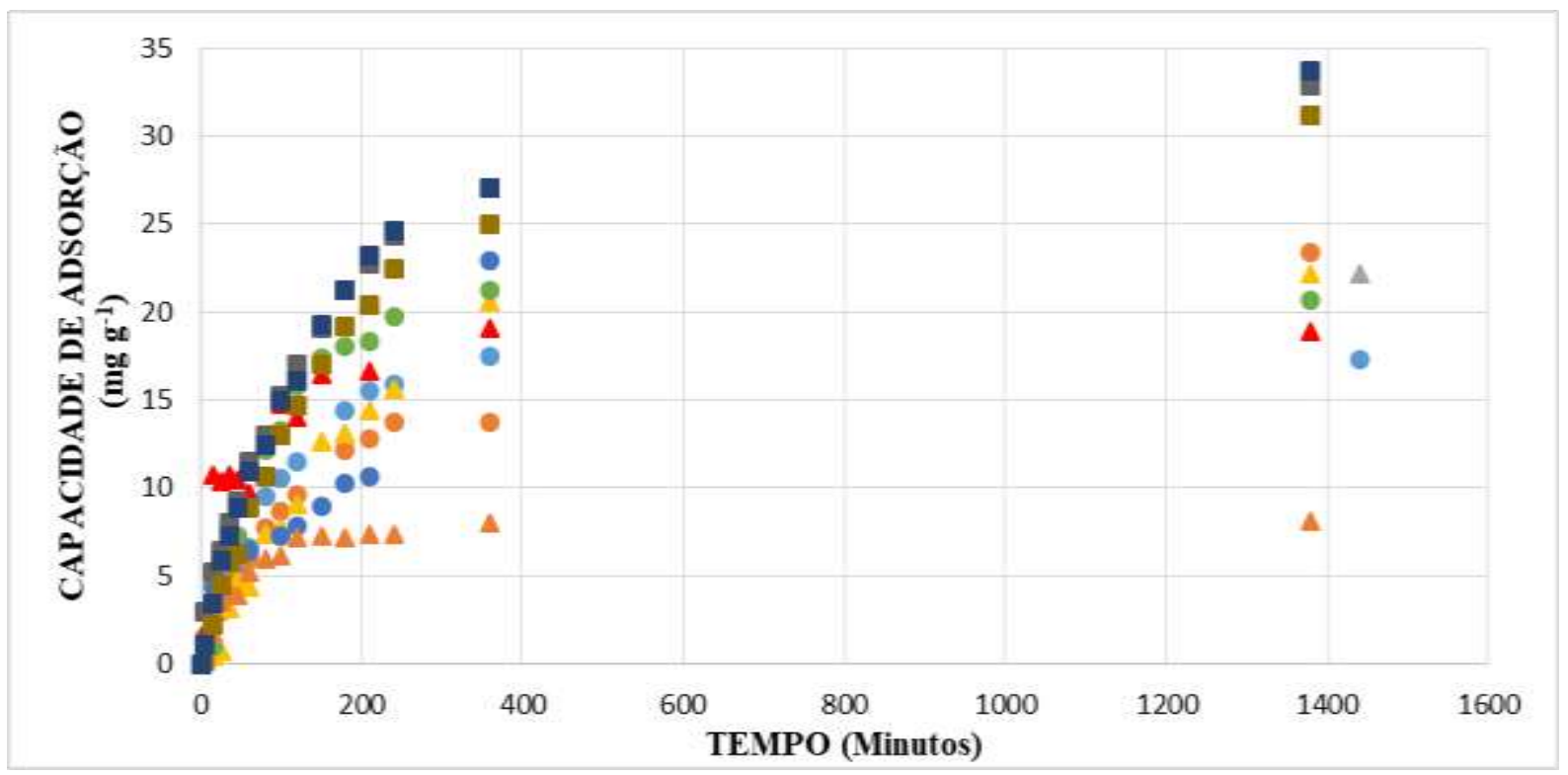

Fonte: Autores. 
Figura 5. Evolução das capacidades de adsorção de DEP em função do tempo em comparação com os resultados positivos: C9 ( $\square), \mathrm{C} 10(\square)$ e $\mathrm{C} 11$ ( $\square)$ em pH 7, 0, $4 \mathrm{~g}, 30^{\circ} \mathrm{C}$ ) e os negativos: $\mathrm{C} 8(\Delta)$ em pH 11, 0,6 g de CA, $45^{\circ} \mathrm{C}$ ).

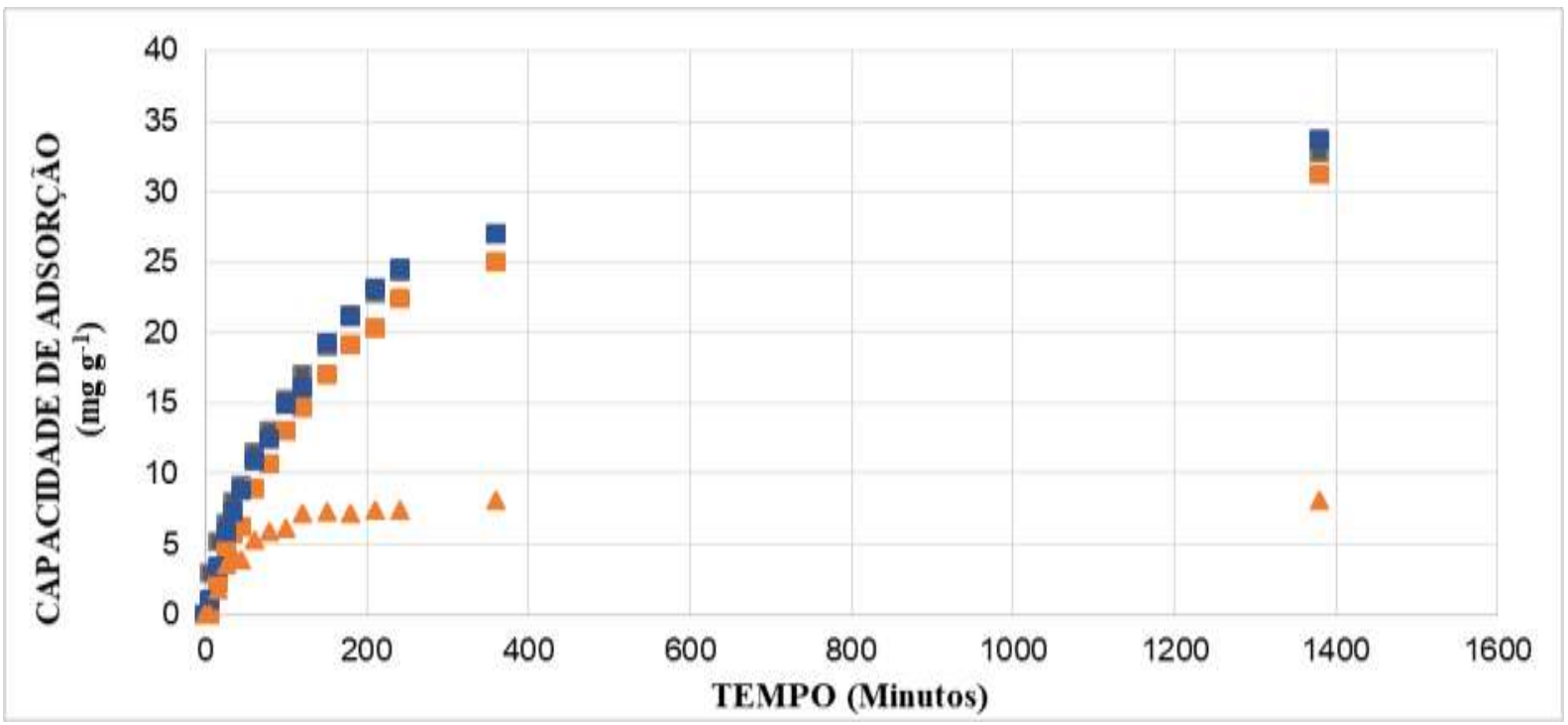

Fonte: Autores.

A Tabela 7 apresenta as respectivas respostas: capacidade de adsorção do CA ( $\left.\mathrm{Y}_{1}\right)$; taxa de eliminação de $\mathrm{DEP}\left(\mathrm{Y}_{2}\right)$; tempo de equilíbrio de adsorção de DEP pelo CA $\left(\mathrm{Y}_{3}\right)$.

Tabela 7. Respostas da capacidade de adsorção do CA $\left(\mathrm{Y}_{1}\right)$; da taxa de eliminação de DEP ( $\left.\mathrm{Y}_{2}\right)$; do tempo de equilíbrio de adsorção de DEP pelo CA ( $\left.\mathrm{Y}_{3}\right)$.

\begin{tabular}{lccc}
\hline Ensaios & $\mathbf{Y}_{\mathbf{1}}\left(\mathbf{m g ~ g}^{-\mathbf{1}}\right)$ & $\mathbf{Y}_{\mathbf{2}} \mathbf{( \% )}$ & $\mathbf{Y}_{\mathbf{3}}$ (minutos) \\
\hline 1 & 17,459 & 14,5 & 360 \\
2 & 13,720 & 55,4 & 360 \\
3 & 20,599 & 13 & 360 \\
4 & 9,165 & 24 & 240 \\
5 & 21,800 & 17,5 & 1260 \\
6 & 21,233 & 46,7 & 1260 \\
7 & 16.460 & 14,1 & 150 \\
8 & 7,220 & 18,6 & 120 \\
9 & 27,007 & 83,5 & 360 \\
10 & 24,980 & 79,9 & 360 \\
11 & 27,025 & 80,3 & 360 \\
\hline
\end{tabular}

Fonte: Autores.

As capacidades de adsorção variaram para cada condição de tratamento e também foram obtidos tempos de equilíbrio variando entre 120 minutos (C8) a 1260 minutos (C5, C6). Entretanto, as maiores capacidade de adsorção e taxas de eliminação de DEP tiveram tempo de equilíbrio em torno de 360 minutos (C9, C10, C11). Conforme, constatado pela caracterização do CA, apresentou menor superfície externa e pouco mesosporos. Isto dificulta o acesso aos microporos 
(Oliveira, 2011c; Zhang et al., 2008), e portanto, demandou maior tempo de equilíbrio para o processo de adsorção de DEP em CA (Venkata-Mohan et al., 2007).

Conforme o resultado determinado para $\mathrm{pH}_{\mathrm{PZC}}$, CA tem um caráter básico $\left(\mathrm{pH}_{\mathrm{PZC}}=7,2\right)$, portanto, tem uma superfície carregada com tendência a positividade nas condições de operação utilizada. Isto pode levar a efeitos repulsão electrostática com o núcleo DEP-ricos em elétrons e, portanto, explicar uma diminuição no desempenho de adsorção em C3 (pH 11, 0,2 g de CA, 15 C). Já que o pH PzC (superfície de CA) < pH (fase aquosa), ou seja, 7,2 < 11, o CA tem superfície também carregada negativamente, além de menor massa de CA e menor temperatura.

\subsubsection{Resultados da análise estatística aplicada à adsorção de DEP em CA}

Variável: capacidade de adsorção $\left(Y_{1}\right)$

Através dos resultados obtidos das cinéticas de adsorção, foram calculados os coeficientes de regressão apresentados na Tabela 8. Observou-se que nenhum coeficiente de regressão foi significativo ao nível de significância de 5\% (p < 0,05).

Tabela 8. Coeficientes de regressão para a resposta $Y_{1}$ (capacidade de adsorção).

\begin{tabular}{|c|c|c|c|c|c|c|}
\hline \multirow[b]{2}{*}{ Fatores } & \multirow[b]{2}{*}{$\begin{array}{l}\text { Coeficiente de } \\
\text { Regressão }\end{array}$} & \multirow[b]{2}{*}{$\begin{array}{c}\text { Erro } \\
\text { padrão }\end{array}$} & \multirow[b]{2}{*}{$t(4)$} & \multirow[b]{2}{*}{ p-valor } & \multicolumn{2}{|c|}{$\begin{array}{c}\text { Estimativas por intervalo } \\
(95 \%)\end{array}$} \\
\hline & & & & & $\begin{array}{l}\text { Limite } \\
\text { inferior }\end{array}$ & $\begin{array}{l}\text { Limite } \\
\text { superior }\end{array}$ \\
\hline Média & 18,78799 & 2,325628 & 8,07867 & 0,001276 & 12,3310 & 25,24496 \\
\hline (x1) Massa & $-3,12243$ & 2,727040 & $-1,14499$ & 0,316067 & $-10,6939$ & 4,44905 \\
\hline \multicolumn{7}{|l|}{$\mathrm{CA}$} \\
\hline (x2) $\mathrm{pH}$ & $-2,59606$ & 2,727040 & $-0,95197$ & 0,395019 & $-10,1675$ & 4,97541 \\
\hline$\left(\mathrm{x}_{3}\right)$ Temp. & 0,72132 & 2,727040 & 0,26451 & 0,804461 & $-6,8502$ & 8,29279 \\
\hline $\mathrm{x}_{1} \mathrm{e} \mathrm{x}_{2}$ & $-2,04584$ & 2,727040 & $-0,75020$ & 0,494849 & $-9,6173$ & 5,52564 \\
\hline $\mathrm{x}_{1} \mathrm{e} \mathrm{x}_{3}$ & 0,67066 & 2,727040 & 0,24593 & 0,817842 & $-6,9008$ & 8,24213 \\
\hline $\mathrm{x}_{2} \mathrm{e}_{3}$ & $-2,24233$ & 2,727040 & $-0,82226$ & 0,457119 & $-9,8138$ & 5,32915 \\
\hline
\end{tabular}

Fonte: Autores.

As superfícies de resposta e o diagrama de Pareto estão apresentadas nas Figuras 6 e 7 a seguir, e confirmam os resultados obtidos experimentalmente, porque mostram exatamente isto, valores maiores de capacidade de adsorção para os menores valores da massa e de $\mathrm{pH}$, já o contrário é apresentado para temperatura. $\mathrm{O}$ efeito é positivo, para esta variável, ou seja diretamente proporcional, quando há aumento da temperatura, tem-se aumento da capacidade de adsorção. A massa, entretanto, não se mostra tão influenciável, como a temperatura, contudo seu efeito negativo é maior se comparado ao efeito também negativo do pH para a capacidade de adsorção.

Deste modo, pode-se afirmar que mesmo nenhum dos fatores terem sido significativos, ainda assim apresentam impacto na capacidade de adsorção de CA. Diante dos resultados obtidos, pode-se também dizer que os três fatores ou variáveis têm amplitudes aproximadas de efeito, também destacado (Dabrowski et al., 2005; Radovic \& Moreno-Castilla, 2001). O processo de adsorção é mais uma interação complexa com fatores diferentes, ao mesmo tempo do que um processo conduzido por um fator principal. Estudo com diferentes fatores mostrou que o CA tem esta complexidade para o processo de adsorção (Fierro et al., 2008; Li et al., 2002). 
Research, Society and Development, v. 10, n. 14, e289101421966, 2021

(CC BY 4.0) | ISSN 2525-3409 | DOI: http://dx.doi.org/10.33448/rsd-v10i14.21966

Figura 6. (a) Superfície de resposta e (b) curva de contorno para Capacidade de adsorção (mg g $\left.\mathrm{g}^{-1}\right)\left(\mathrm{Y}_{1}\right)$ em função da temperatura $\left({ }^{\circ} \mathrm{C}\right)$ e massa da carvão ativado $(\mathrm{g})$;

\section{Superficie de Resposta; Variável: Capacidade de adsorção ( $\mathrm{mg} / \mathrm{g})$

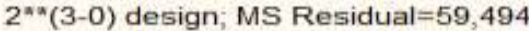

DV: Capacidade de adsorção $(\mathrm{mg} / \mathrm{g})$
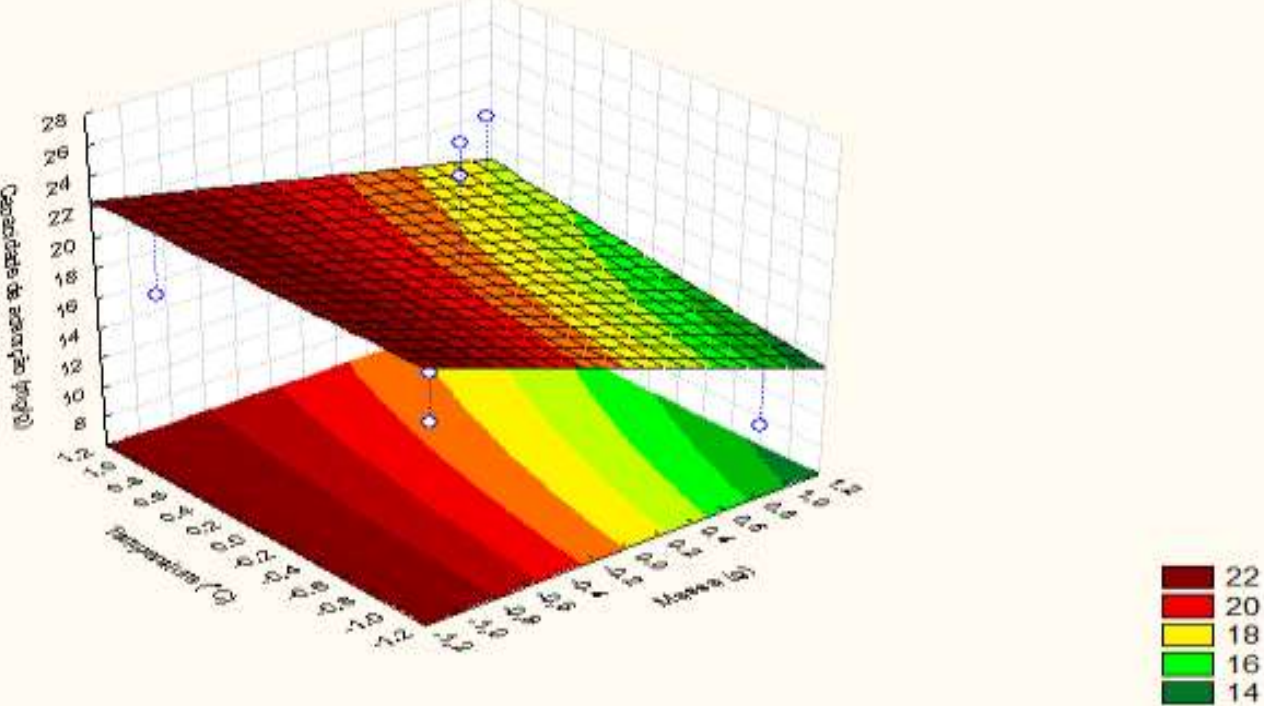

(a)

Curva de Contorno; Variável: Capacidade de adsorção $(\mathrm{mg} / \mathrm{g})$ $2^{\star \star}(3-0)$ design; MS Residual $=59,494$

DV: Capacidade de adsorçăo $(\mathrm{mg} / \mathrm{g})$

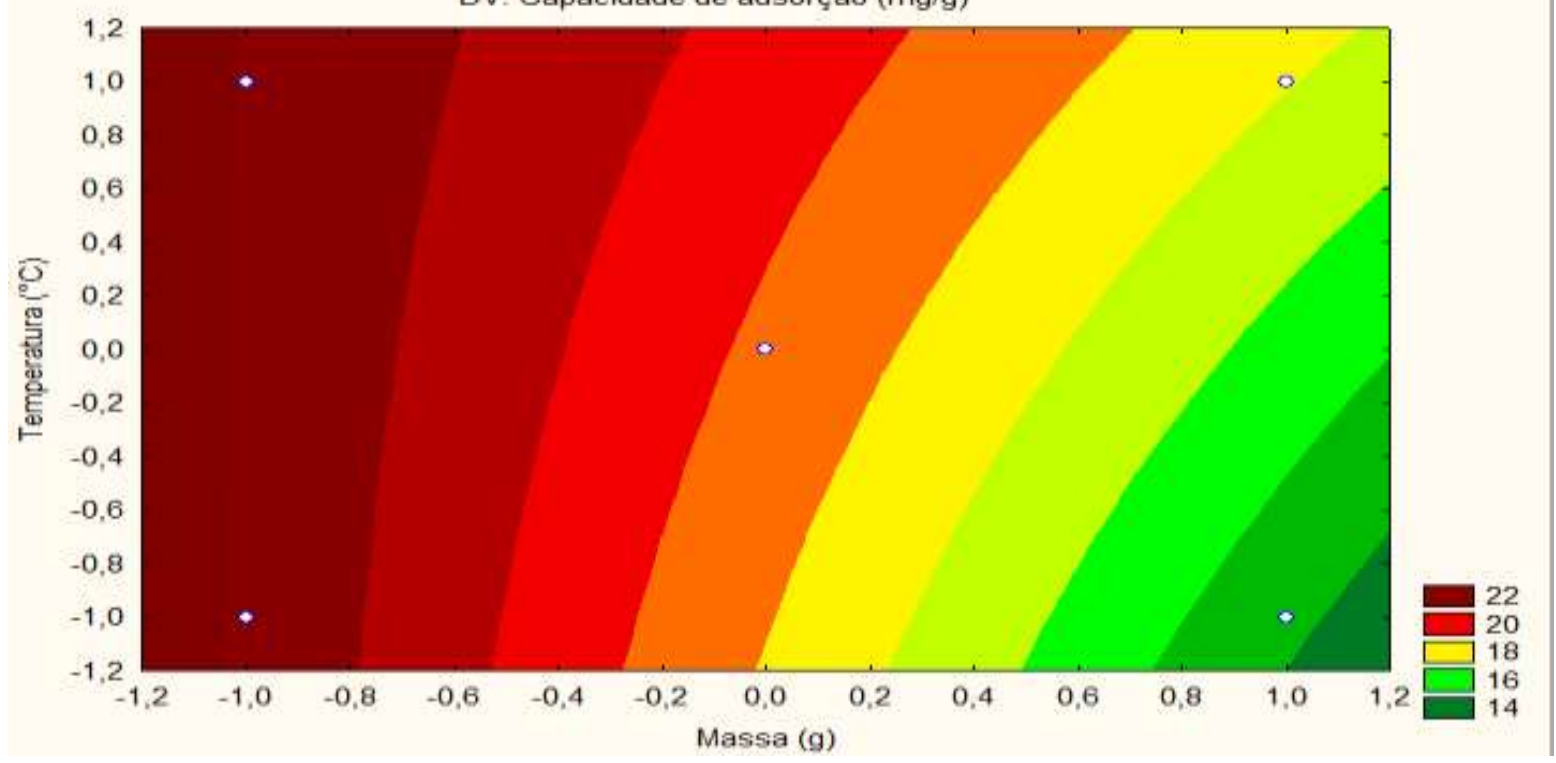

(b) 
Research, Society and Development, v. 10, n. 14, e289101421966, 2021

(CC BY 4.0) | ISSN 2525-3409 | DOI: http://dx.doi.org/10.33448/rsd-v10i14.21966

Figura 6. (c) Superfície de resposta e (d) curva de contorno para Capacidade de adsorção (mg g $\left.{ }^{-1}\right)\left(\mathrm{Y}_{1}\right)$ em função do pH e da massa de carvão ativado (g).

Superfície de Resposta; Variável: Capacidade de adsorção $(\mathrm{mg} / \mathrm{g})$

$2^{* \star}(3-0)$ design; MS Residual $=59,494$

DV: Capacidade de adsorção $(\mathrm{mg} / \mathrm{g})$

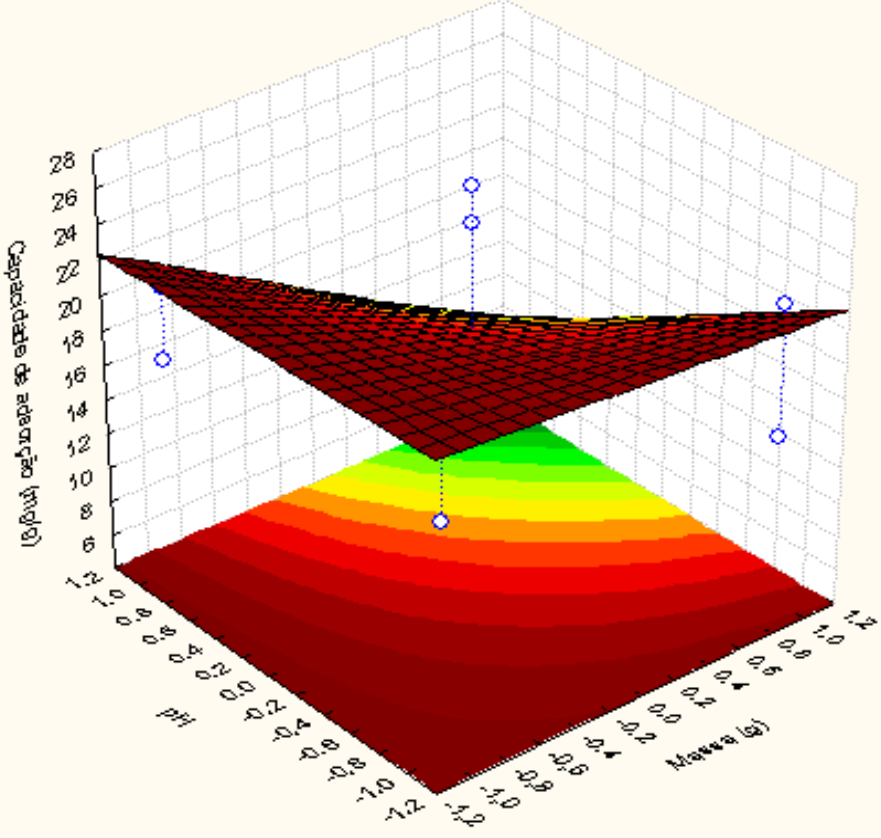

(c)

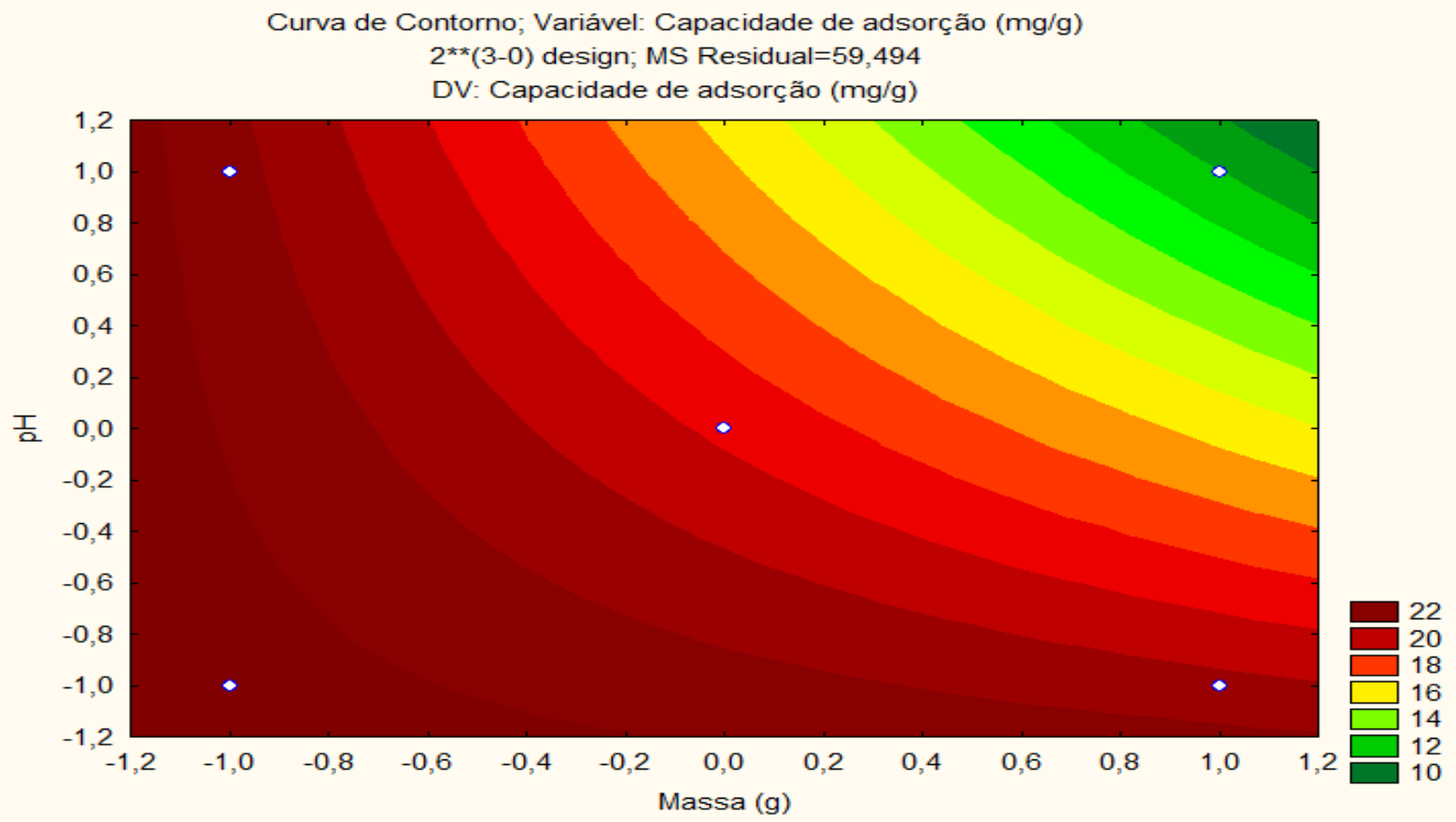

(d) 
Research, Society and Development, v. 10, n. 14, e289101421966, 2021

(CC BY 4.0) | ISSN 2525-3409 | DOI: http://dx.doi.org/10.33448/rsd-v10i14.21966

Figura 6. (e) Superfície de resposta e (f) curva de contorno para Capacidade de adsorção ( $\left.\mathrm{mg} \mathrm{g}^{-1}\right)\left(\mathrm{Y}_{1}\right)$ em função da temperatura $\left({ }^{\circ} \mathrm{C}\right)$ e do $\mathrm{pH}$.

Superfície de Resposta; Variável: Capacidade de adsorção (mg/g)

$2^{\star \star \star}(3-0)$ design; MS Residual $=59,494$

DV: Capacidade de adsorção $(\mathrm{mg} / \mathrm{g})$

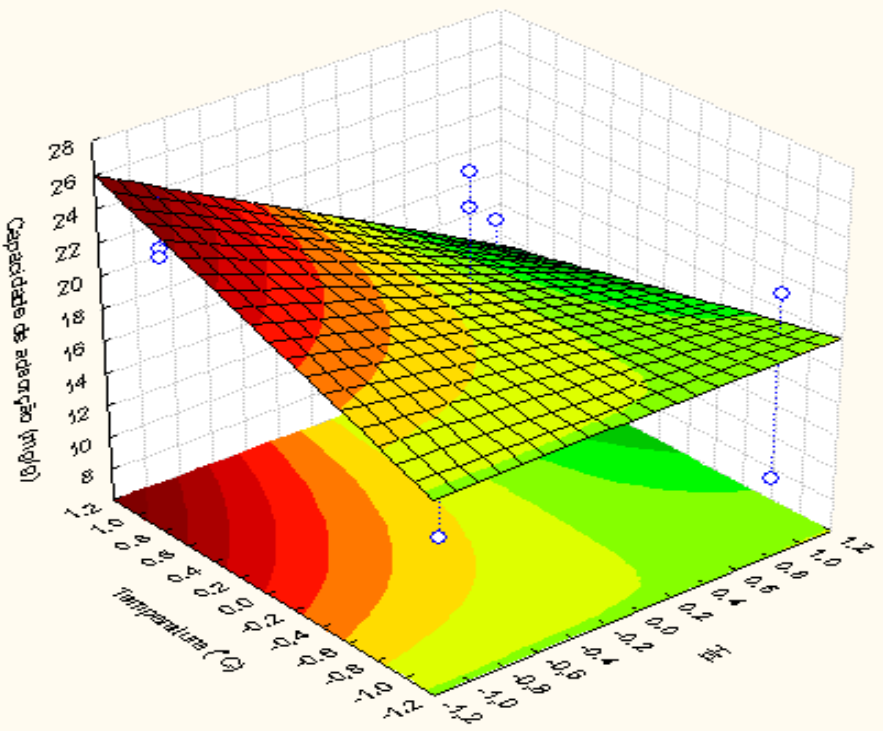

(e)

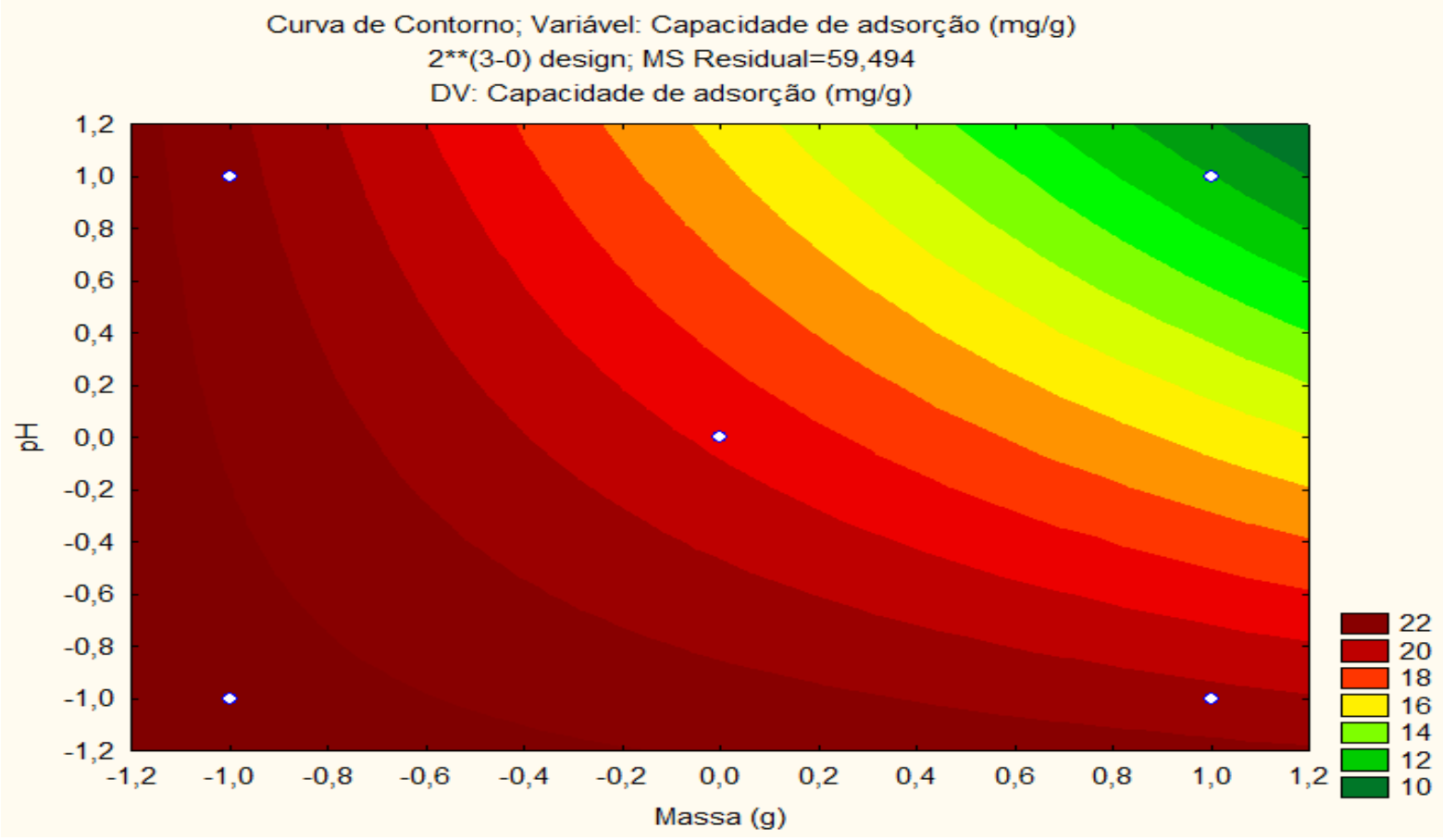

(f)

Fonte: Autores. 
Figura 7. Diagrama de Pareto dos efeitos padronizados para resposta $\mathrm{Y}_{1}$ (capacidade de adsorção).

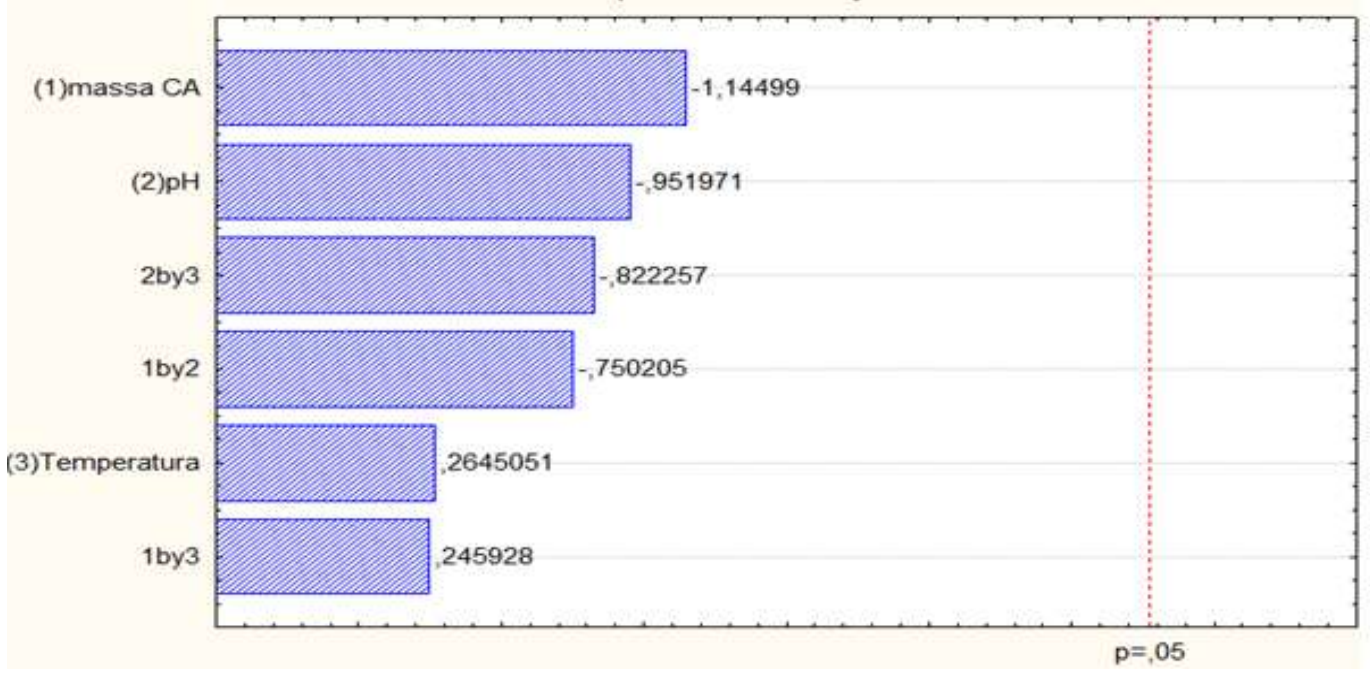

Estimativa de efeito padronizado (valor absoluto) . Fonte: Autores.

Variável: taxa de eliminação de DEP por adsorção em $C A\left(Y_{2}\right)$

Através dos resultados obtidos, foram calculados os coeficientes de regressão apresentados na Tabela 9 e o gráfico de Pareto (Figura 8). Observou-se que os coeficientes de regressão para $\mathrm{x}_{1}$ e a interação entre $\mathrm{x}_{2}$ e $\mathrm{x}_{3}$ não foram significativas ao nível de significância de $5 \%(\mathrm{p}<0,05)$.

$\mathrm{O}$ aumento da taxa de eliminação do ftalato $\left(\mathrm{Y}_{2}\right)$ foi em decorrência ao aumento da massa de carvão $\left(\mathrm{x}_{1}\right)$, conforme pode ser observado na Tabela 9 dos coeficientes de regressão para essa resposta. Deste modo, as características químicas e físicas do CA, como sua porosidade, influenciaram de modo positivo para esta resposta. Essa relação entre as características do CA e a afinidade por meio de interações eletrostáticas e/ou dispersivas com a molécula de DEP, baseia-se nos fundamentos de transferência de massa e mecanismos de fisiosorção entre a molécula de DEP e a superfície do CA.

Tabela 9. Coeficiente de regressão para a resposta $Y_{2}$ (taxa de eliminação de DEP).

\begin{tabular}{|c|c|c|c|c|c|c|}
\hline \multirow[b]{2}{*}{ Fatores } & \multirow[b]{2}{*}{$\begin{array}{l}\text { Coeficiente de } \\
\text { Regressão }\end{array}$} & \multirow[b]{2}{*}{$\begin{array}{c}\text { Erro } \\
\text { padrão }\end{array}$} & \multirow[b]{2}{*}{$t(4)$} & \multirow[b]{2}{*}{ p-valor } & \multicolumn{2}{|c|}{$\begin{array}{c}\text { Estimativas por intervalo } \\
(95 \%)\end{array}$} \\
\hline & & & & & $\begin{array}{l}\text { Limite } \\
\text { inferior }\end{array}$ & $\begin{array}{c}\text { Limite } \\
\text { superior }\end{array}$ \\
\hline Média. & 40,6818 & 12,42653 & 3,273787 & 0,030680 & 6,1802 & 75,18340 \\
\hline$\left(\mathrm{x}_{1}\right)$ Massa & 21,4000 & 29,14280 & 0,734315 & 0,503480 & $-29,7567$ & 51,15669 \\
\hline \multicolumn{7}{|l|}{$\mathrm{CA}$} \\
\hline$\left(\mathrm{x}_{2}\right) \mathrm{pH}$ & $-16,1000$ & 29,14280 & $-0,552452$ & 0,610055 & $-48,5067$ & 32,40669 \\
\hline$\left(\mathrm{x}_{3}\right)$ Temp. & $-2,5000$ & 29,14280 & $-0,085784$ & 0,935760 & $-41,7067$ & 39,20669 \\
\hline $\mathrm{x}_{1}$ e $\mathrm{x}_{2}$ & $-13,6500$ & 29,14280 & $-0,468383$ & 0,663895 & $-47,2817$ & 33,63169 \\
\hline $\mathrm{x}_{1}$ e $\mathrm{x}_{3}$ & $-4,5500$ & 29,14280 & $-0,156128$ & 0,883495 & $-42,7317$ & 38,18169 \\
\hline $\mathrm{x}_{2} \mathrm{e} \mathrm{x}_{3}$ & 0,3500 & 29,14280 & 0,012010 & 0,990993 & $-40,2817$ & 40,63169 \\
\hline
\end{tabular}

Fonte: Autores. 
Figura 8. Diagrama de Pareto dos efeitos padronizados para resposta $\mathrm{Y}_{2}$

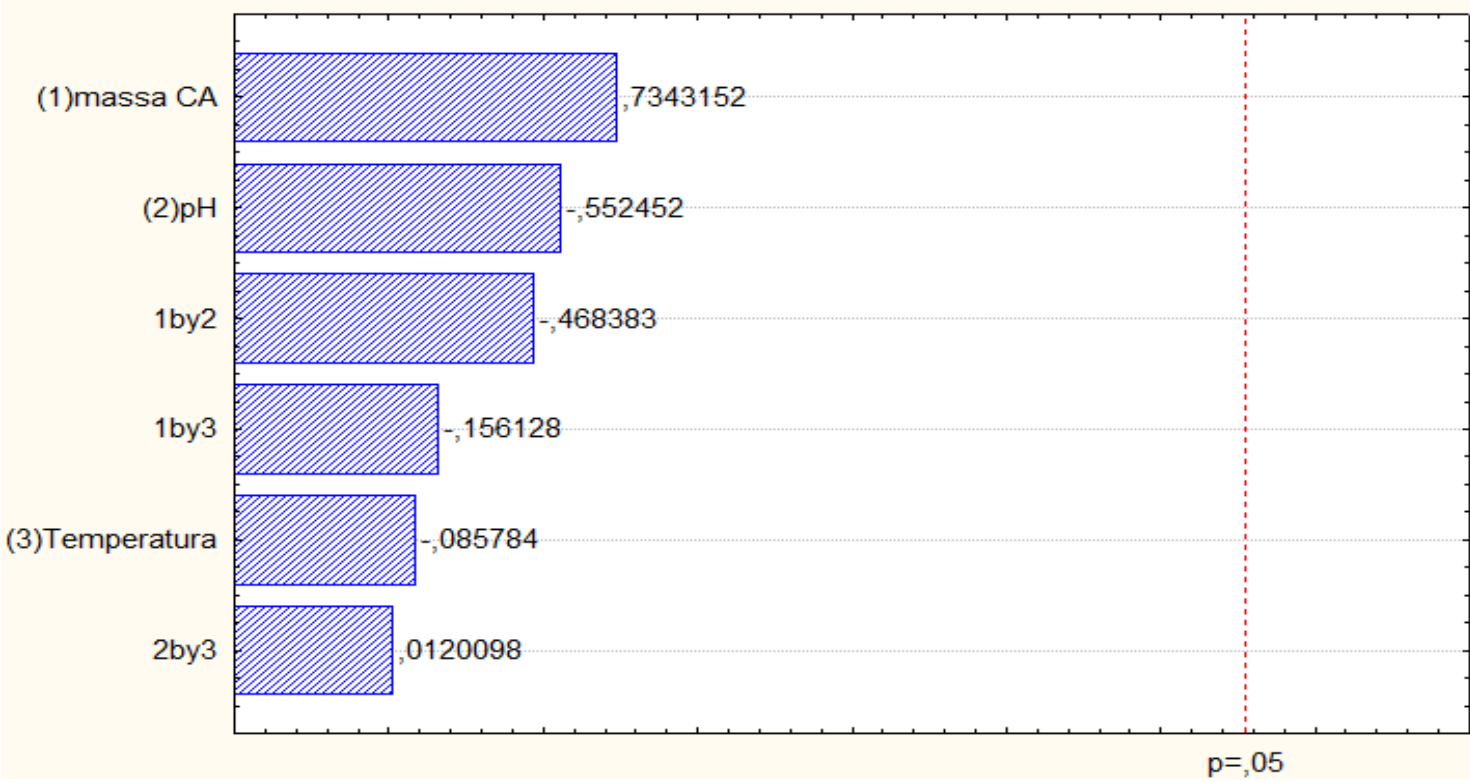

Estimativa de efeito padronizado (valor absoluto)

Fonte: Autores.

\subsubsection{Modelagem matemática das cinéticas de adsorção}

Os dados das onze cinéticas de adsorção foram submetidos aos modelos de pseudo-primeira e pseudo-segunda ordem e modelo intrapartícula para descrever a cinética de adsorção sobre CA pela compreensão dos fenômenos na interface entre CA e as moléculas de poluentes em termos de difusão e mecanismo de adsorção. Os resultados estão apresentados nas Tabelas 10, 11 e 12 das modelagens aplicadas às cinéticas de adsorção.

Tabela 10. Parâmetros cinéticos do modelo de pseudo-primeira ordem aplicado ao tratamento de adsorção de DEP em CA.

\begin{tabular}{cc|cccc}
\hline CA & $\begin{array}{c}\text { qe exp } \\
\left(\mathbf{m o l ~ g}^{-1}\right)\end{array}$ & $\begin{array}{c}\text { qe calc } \\
\left(\mathbf{m o l ~ g}^{-1}\right)\end{array}$ & $\Delta$ (qe cal-qe exp) & $\begin{array}{c}\text { k1 } \\
\left(\mathbf{m i n}^{-1}\right)\end{array}$ & $\mathbf{R}_{\mathbf{1}}{ }^{2}$ \\
\hline C1 & 17,4589 & 18,1719 & 0,7130 & 0,0101332 & 0,9941 \\
C2 & 13,7199 & 14,3450 & 0,6251 & 0,0113 & 0,9814 \\
C3 & 20,5986 & 22,3769 & 1,7783 & 0,0062 & 0,9862 \\
C4 & 9,1653 & 9,8243 & 0,6590 & 0,0113 & 0,9604 \\
C5 & 21,8004 & 19,5659 & $-2,2345$ & 0,0023 & 0,6367 \\
C6 & 19,7472 & 22,6569 & 2,9097 & 0,0138 & 0,9897 \\
C7 & 16,4598 & 7,4731 & $-8,9867$ & 0,0032 & 0,0598 \\
C8 & 7,2200 & 7,1007 & $-0,1194$ & 0,0203 & 0,9725 \\
C9 & 27,0068 & 26,5461 & $-0,4607$ & 0,0088 & 0,9893 \\
C10 & 24,9805 & 27,0085 & 2,0280 & 0,0088 & 0,9805 \\
C11 & 27,0247 & 28,3204 & 1,2957 & 0,0092 & 0,9834 \\
\hline
\end{tabular}

Fonte: Autores. 
Tabela 11. Parâmetros cinéticos do modelo de pseudo-segunda ordem aplicado ao tratamento de adsorção de DEP em CA.

\begin{tabular}{|c|c|c|c|c|c|}
\hline \multirow[b]{2}{*}{$\mathbf{C A}$} & \multirow[b]{2}{*}{$\begin{array}{c}\text { qe exp } \\
\left(\mathrm{mol} \mathrm{g}^{-1}\right)\end{array}$} & \multicolumn{4}{|c|}{ Modelo pseudo-segunda ordem } \\
\hline & & $\begin{array}{c}\text { qe calc } \\
\left(\mathrm{mol} \mathrm{g}^{-1}\right)\end{array}$ & $\Delta\left(q_{\text {e cal- }}-q_{\text {e exp }}\right)$ & $\begin{array}{c}\mathrm{k}_{2} \\
\left(\mathrm{~g} \mathrm{mg}^{-1} \mathrm{~min}^{-1}\right)\end{array}$ & $\mathbf{R}_{2}^{2}$ \\
\hline $\mathrm{C} 1$ & 17,458875 & 18,348624 & 0,889749 & 0,000727 & 0,9955 \\
\hline $\mathrm{C} 2$ & 13,719856 & 26,109661 & 12,389805 & 0,000193 & 0,9955 \\
\hline $\mathrm{C} 3$ & 20,598603 & 32,679739 & 12,081135 & 0,000071 & 0,5219 \\
\hline $\mathrm{C} 4$ & 9,165257 & 10,131712 & 0,966455 & 0,001310 & 0,9948 \\
\hline $\mathrm{C} 5$ & 21,800376 & 24,752475 & 2,952100 & 0,000222 & 0,9426 \\
\hline C6 & 19,747190 & 31,250000 & 11,502810 & 0,000223 & 0,9556 \\
\hline $\mathrm{C} 7$ & 16,459770 & 19,455253 & 2,995483 & 0,001517 & 0,9981 \\
\hline $\mathrm{C} 8$ & 7,220039 & 8,354219 & 1,134179 & 0,003582 & 0,9987 \\
\hline C9 & 27,006775 & 35,460993 & 8,454218 & 0,000245 & 0,9963 \\
\hline $\mathrm{C} 10$ & 24,980485 & 35,587189 & 10,606704 & 0,000159 & 0,9956 \\
\hline $\mathrm{C} 11$ & 27,024719 & 37,735849 & 10,711130 & 0,000180 & 0,9987 \\
\hline
\end{tabular}

Fonte: Autores.

Tabela 12. Parâmetros cinéticos do modelo intrapartícula aplicado ao tratamento de adsorção de DEP em CA.

\begin{tabular}{lccc}
\hline & \multicolumn{1}{c}{ Modelo intrapartícula } & \\
\hline CA & $\mathbf{c} \mathbf{R}^{\mathbf{2}}$ & \\
\hline C1 & $\begin{array}{c}\mathbf{k}_{\text {dif }} \\
\left(\mathbf{m o l ~ g ~}^{-\mathbf{1}} \mathbf{~ m i n}^{-\mathbf{1} / \mathbf{2}}\right)\end{array}$ & 0,512800 & 0,6748 \\
C2 & 3,521700 & 0,674000 & 0,9424 \\
C3 & 0,979200 & 0,738400 & 0,8058 \\
C4 & 0,655700 & 0,258900 & 0,6387 \\
C5 & 2,226800 & 0,604900 & 0,9473 \\
C6 & 0,974100 & 1,3772 & 0,9493 \\
C7 & 1,5921 & 0,4674 & 0,5789 \\
C8 & 7,0917 & 0,2101 & 0,5622 \\
C9 & 3,1552 & 0,9878 & 0,8455 \\
C10 & 4,0531 & 0,995400 & 0,8511 \\
C11 & 1,806900 & 1,046100 & 0,8476 \\
\hline
\end{tabular}

Fonte: Autores.

A avaliação quantitativa dos modelos foi realizada pela comparação dos coeficientes de determinação $\left(\mathrm{R}^{2}\right)$. Estes foram mais elevados, $\mathrm{R}^{2}>$ 0,99, para o modelo de pseudo-segunda ordem, confirmando que o processo de adsorção se ajusta melhor ao mecanismo de pseudo-segunda ordem em maior parte das variações de condição de tratamento. O melhor ajuste ao mecanismo de pseudo-segunda-ordem foi também confirmado pela proximidade obtida entre os valores de $\mathrm{q}_{\mathrm{e}}$ determinados experimentalmente $\left(\mathrm{q}_{\mathrm{e}}\right.$ exp) com os valores de $\mathrm{q}_{\mathrm{e}}$ calculados $\left(\mathrm{q}_{\mathrm{e}}\right.$ calc) pelos modelos (Tabela 11). As diferenças entre os valores experimentais da capacidade de adsorção para o equilíbrio e aqueles calculado pelo modelo de pseudo-segunda ordem são baixos $(<10 \%)$ pra maioria.

De acordo com os resultados apresentados na Tabela 12, é possível verificar que o tratamento de adsorção de DEP com CA não se ajustou ao modelo intrapartícula. Estes resultados mostram, portanto, que a difusão externa, neste caso, não 
desempenhou um papel importante no processo de adsorção de DEP, e também não foi mecanismo predominante em estudos de equilíbrio e modelagem cinética da adsorção do corante cristal violeta sobre zeólitas de cinzas leve e pesada de carvão (Bertoni \& Fungaro, 2011). A dificuldade de difusão deu-se pela morfologia das partículas de CA e tamanho da molécula do poluente.

\subsection{Isotermas de adsorção de DEP em CA}

As isotermas de adsorção estudadas foram repetições das condições das cinéticas $\mathrm{C} 9\left(\mathrm{pH} 7-0,4 \mathrm{~g} \mathrm{CA}-30^{\circ} \mathrm{C}\right)$, a qual se obteve maior capacidade de adsorção de DEP, e também maior taxa de eliminação, em 360 minutos; C8 (pH 11 - 0,6 g $\mathrm{CA}-45^{\circ} \mathrm{C}$ ), apresentou a menor capacidade de adsorção e uma das menores taxas de eliminação de DEP, entretanto com menor tempo de equilíbrio, apenas 120 minutos; e $\mathrm{C} 6\left(\mathrm{pH} 3-0,6 \mathrm{~g} \mathrm{CA}-45^{\circ} \mathrm{C}\right)$, mostrou uma considerável capacidade de adsorção de DEP, mas uma da taxas de eliminação de DEP de 46,7\%, muito aquém da condição ótima (C9), e também o maior tempo de equilíbrio determinado em 1260 minutos.

A isoterma de adsorção é representada pela curva entre a capacidade de adsorção em $\mathrm{q}_{\mathrm{e}}$ equilíbrio $\left(\mathrm{mg} \mathrm{g}^{-1}\right.$ ) em função da concentração de equilíbrio de $\mathrm{C}_{\mathrm{e}}\left(\mathrm{L} \mathrm{mol}^{-1}\right)$. Os resultados das isotermas de adsorção DEP em CA de C9, C8 e C6 são mostrados na Figura 9 e Tabela 13.

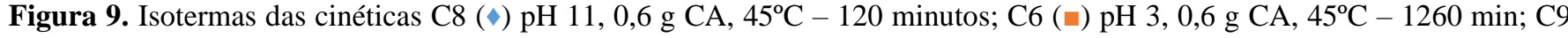
$(\triangle) \mathrm{pH} 7,0,0,4 \mathrm{~g}$ de $\mathrm{CA}, 30^{\circ} \mathrm{C}-360 \mathrm{~min}$ ), são apresentadas as capacidades de adsorção em qe equilíbrio ( $\left.\mathrm{mg} \mathrm{g}^{-1}\right)$ como uma função da concentração de equilíbrio de $\mathrm{C}_{\mathrm{e}}\left(\mathrm{mg} \mathrm{L}^{-1}\right)$ destas condições experimentais.

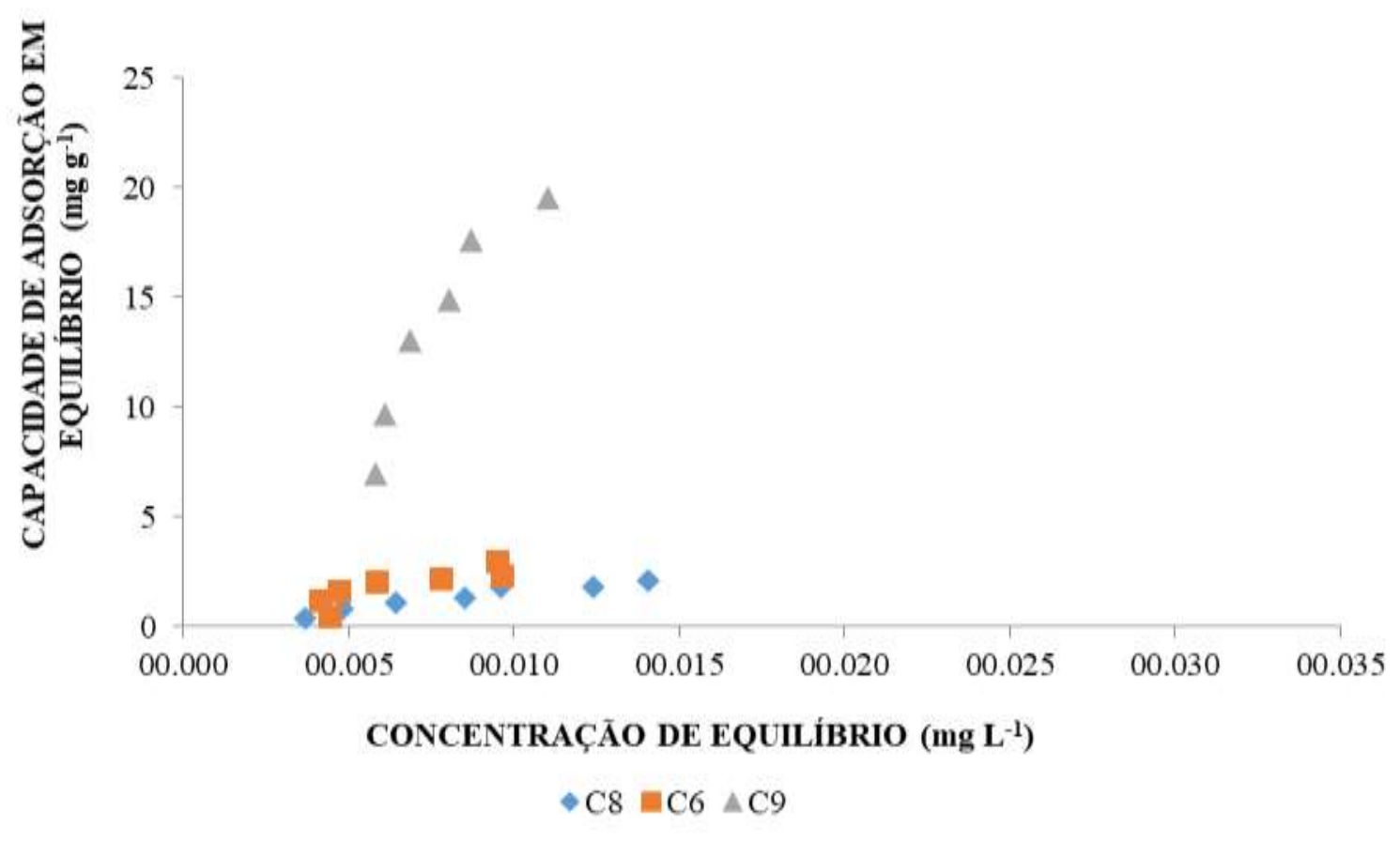

Fonte: Autores. 
Tabela 13. Capacidade de adsorção no equilíbrio para o CA nas condições experimentais de C9, C8 e C6 nas isotermas.

\begin{tabular}{lcc}
\hline Cinética & $\begin{array}{c}\text { Capacidade máxima de adsorção no } \\
\text { tempo de equilibrio }\left(\mathbf{m g ~ g}^{-\mathbf{1}}\right)\end{array}$ & $\begin{array}{c}\text { Taxa de eliminação de DEP no tempo de } \\
\text { equilibrio (\%) }\end{array}$ \\
\hline C9 & 23,789 & 75,5400 \\
C8 & 5,802 & 41,0746 \\
C6 & 5,720 & 59,0991 \\
\hline
\end{tabular}

Fonte: Autores.

Estes resultados mostram que o CA no equilíbrio a condição C9 têm na extremidade um concentração de equilíbrio $\left(\mathrm{C}_{\mathrm{e}}\right)$ menor e, alcançou a maior capacidade de adsorção de $23,79 \mathrm{mg} \mathrm{g}^{-1}$, assim como, no delineamento experimental cinético. Já a condição $\mathrm{C} 8$, no equilíbrio, em concentrações $\left(\mathrm{C}_{\mathrm{e}}\right)$ maior, teve a menor capacidade de adsorção, com taxas de eliminação

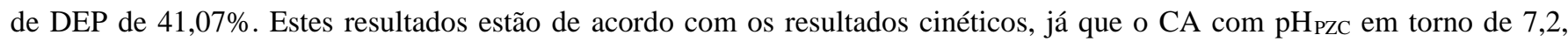
então é carregado com tendência a positividade (considera-se básica, contudo próximo ao equilíbrio entre os grupos ácidos e básicos na superfície), quando o $\mathrm{pH}$ do meio está próximo ou igual ao $\mathrm{pH}$ PZC do CA.

Quando o $\mathrm{pH}>$ pHPZC, logo, a sua capacidade de adsorção é menor, pois ocorre a predominância de forças de repulsão eletrostática entre a superfície do CA e o anel aromático do DEP, pois tanto a superfície de CA como a molécula de DEP tem carga superficial negativa, o que foi confirmado pelas condições do meio aquoso com pH 11 (C8). Também se deve ao fato de que o carvão não apresenta superficie de mesoporos maior que de microporos, então não é favorecida a fisiossorção. Já com o pH < pH PZC, a capacidade de adsorção também foi baixa, já que o carvão não apresentou superficie com interação forte entre seus grupos ácidos, por não ter característica ácida e sim neutra com tendência para básica. Embora, mesmo o CA carregado positivamente em pH ácido, não há força predominante de atração eletrostática entre a superfície do CA e o anel aromático do DEP, o que foi confirmado pelas condições do meio aquoso com pH 3 (C6).

Existem várias pesquisas com foco na eliminação de micropoluentes, e a adsorção é um método eficaz para separar os ésteres de ftalato (PAEs) da fase aquosa e muitos adsorventes foram considerados na litetarura, como CA, adsorvente polimérico, nanotubo de carbono, quitosana e algas marinhas. A adsorção de dibutil ftalato (DBP) em CA é espontânea e endotérmica e favorece temperaturas mais elevadas (Fang \& Huang, 2009). As resinas poliméricas foram descritas para eliminar a DEP em meio aquoso e os processos de adsorção são limitados pelo filme e difusões intraparticulares (Xu et al., 2011). Nanomateriais, como o nanotubo de carbono, também adsorveram dimetil ftalato (DMP) e DEP, e o desempenho é influenciado pelo tamanho do nanotubo, modificação de superfície, e temperatura de adsorção (Den et al., 2006). Alga marinha adsorvente de biomassa, pode remover di-2-etilhexil ftalato (DEHP) com capacidade de adsorção de 5,68-6,54 mg $\mathrm{g}^{-1}$ num teste em batelada (Chan et al., 2004).

Resultados publicados acerca da remoção de ftalatos por adsorção foram analisadas em revisão da literatura por Gani \& Kazmi (2016), e então, afirmaram que a adsorção é relatada como uma das opções de tratamento eficaz, assim como em outras pesquisas (Venkata-Mohan et al., 2007; Mendez-Diaz et al., 2010; Wang et al., 2010; Julinová \& Slavik, 2012). Venkata-Mohan et al. (2007) relataram 53,2-82,6\% de remoção de DEP por adsorção com CA. Outros adsorventes, tais como grânulos de quitosana e resinas poliméricas, também foram investigadas para remoção de ftalato e sua eficiência de remoção é relatada em 90\% (Xu et al., 2008, Salim et al., 2010).

A temperatura também afeta a adsorção de ftalatos e o efeito é principalmente observado nos casos em que a adsorção ocorre por difusão intraparticular. Uma temperatura mais elevada aumenta a velocidade de difusão das moléculas de ftalato nos poros do adsorvente e a energia é derivada do calor circundante. Fang \& Huang (2009) relataram que a capacidade 
de adsorção de NAC (carvão ativado de casca de noz) aumentou de 40,1 para 104,7 $\mathrm{mg} \mathrm{g}^{-1}$ quando a temperatura foi aumentada de $25-55^{\circ} \mathrm{C}$. Adsorção de DEP em nanotubos de carbono multicamadas (MWCNTs) também foi observado como endotérmica e aumenta com a temperatura, já que se determinou que a capacidade de adsorção foi de $6 \mathrm{mg} \mathrm{g}^{-1}$ a $288 \mathrm{~K}$ $\left(14,85^{\circ} \mathrm{C}\right)$ a $10 \mathrm{mg} \mathrm{g}^{-1}$ a $308 \mathrm{~K}\left(34,85^{\circ} \mathrm{C}\right)$, em nanotubo com diâmetro interno de carbono de 10-20 nm por Den et al. (2006). Além do aumento na taxa de eliminação com a temperatura, os autores também relataram redução na tensão superficial de DEP a temperaturas mais elevadas como razão possível para mais adsorção.

Julinova e Slavik (2012) apresentaram uma revisão de materiais adsortivos propostos e testados para remoção de ftalatos a partir de um ambiente aquoso e relatou tipos selecionados de materiais inovadores. Exemplos incluem CA, quitosana e suas modificações, $\beta$-ciclodextrina e tipos específicos de biomassa, lodo ativado de uma estação de tratamento de águas residuais, algas marinhas e culturas microbianas. Afirmam que dados da literatura não confirmam a existência de um adsorvente de espectro amplo com elevada eficiência de custos de produção e manufatura ambientalmente amigável. Relatam que a adsorção parece ser uma ferramenta eficiente para maiores quantidades de águas residuais contendo ftalatos. $\mathrm{O}$ uso de materiais adsortivos comerciais (CA, coque, peneiras moleculares de carbono, tecidos de carbono, resinas de permuta iónica, hidróxido de magnésio e outros) pode ser utilizado para adsorção de substâncias orgânicas, cuja eficiência é relativamente elevada, mas é sobrecarregado pela desvantagem de um preço mais elevado. Outra opção é a utilização de adsorventes naturais (carvão, humatos, ácidos húmicos, algas marinhas e outros), cujo preço é incomparavelmente menor, mas a sua capacidade de sorção é limitada.

A adsorção de ftalatos em CA e por CA modificado é relevante, são tipos de adsorventes há muito considerados capazes de adsorver estes micropoluentes. Por exemplo: Venkata-Mohan et al. (2007) enfocaram no estudo de sorção de DEP em CA a partir da fase aquosa, utilizando carvão de tamanho médio geométrico de $70 \mathrm{~mm}$ (área de superfície $500 \mathrm{~m}^{2} \mathrm{~g}^{-1}$ ) como adsorvente.

A capacidade de adsorção de CA estudada pelos autores nas seguintes condições: temperatura de $30^{\circ} \mathrm{C}$, velocidade de agitação de $100 \mathrm{rpm}, \mathrm{pH} 7$, uma concentração de DEP de $1 \mathrm{mg} \mathrm{L}^{-1}$, durante um período de $120 \mathrm{~min}$. A quantidade de CA foi escolhida na faixa de 0,2 e $1 \mathrm{mg} \mathrm{L}^{-1}$. A maior eficiência foi alcançada com $1 \mathrm{mg} \mathrm{L}^{-1}$ de CA, então a sorção de DEP aumenta com quantidade de adsorvente. A influência do pH na adsorção de ftalatos foi esclarecida por Venkata-Mohan et al. (2007) como segue: os fenômenos de adsorção de ftalatos podem ser explicados com base em hidrofóbicos e efeitos dispersivos. Os fenômenos de sorção de DEP em pH neutro pode ser atribuído a interações hidrofóbicas que são caracterizadas como atração extraordinariamente forte por Moreno-Castilla (2004) entre sítios hidrofóbicos de superfície do CA e o grupo apolar alquil, ou são grupos alil de ftalatos que determinam a ordem da taxa e extensão da adsorção (Ayranci \& Bayram, 2005).

Os dados obtidos de adsorção de DEP são altamente dependentes sobre o valor de $\mathrm{pH}$; um aumento do $\mathrm{pH}$ provoca a alteração da eficiência da adsorção, diminuiu de cerca de $80 \%$ para cerca de 50\%. A eficiência máxima foi alcançado a pH 2. Em pH ácido, o efeito protonado de grupos funcionais de superfície tais como como amino, carboxilo, tiol, etc., conferiram uma carga positiva da superfície (Ilhami et al., 2005). A inibição de sorção observada em todo o intervalo de pH básico pode ser atribuída a um aumento do íon hidroxil, conduzindo à formação de aqua-complexos, que retardam, assim, a sorção (Venkata-Mohan et al., 2002; 2007).

Fang e Huang (2009) estudaram a adsorção do dibutil ftalato (DBP) em CA à base de casca de noz (área BET 1224 $\mathrm{m}^{2} \mathrm{~g}^{-1}$ ). Os autores do trabalho descobriram o seguinte: uma baixa concentração de DBP causou a taxa de adsorção de DBP no CA de casca de noz (NAC) por ser lenta e a capacidade de sorção foi baixa. Isso indica que a interação entre DBP e NAC é fraca em baixo níveis de concentração de DBP. Ao mesmo tempo, verificou-se que a a capacidade de adsorção de NAC aumenta de 40,1 $\mathrm{mg} \mathrm{g}^{-1}$ para $104,7 \mathrm{mg} \mathrm{g}^{-1}$ com um aumento da temperatura $\left(25\right.$ e $\left.55^{\circ} \mathrm{C}\right)$, o que sugere que este é um processo endotérmico afetado pela difusão intrapartícula. Isto significa que o aumento da temperatura aumenta a velocidade das 
moléculas de DBP, enquanto a resistência à difusão diminui, aumentando a capacidade de adsorção de NAC. O tempo necessário para a realização do equilíbrio dependia da concentração de DBP (3 e $6 \mathrm{mg} \mathrm{L} \mathrm{L}^{-1}$ ), com o tempo de 40 h, os autores atribuíram, então, como o melhor para todos os níveis de concentração. O motivo desse aumento, de acordo com os autores, foi que as maiores concentrações do adsorvato proporcionaram força motriz suficiente para resistência à transferência de massa de DBP entre a solução aquosa e a superfície adsorvente (Fang \& Huang, 2009).

O impacto do adsorvente sobre a adsorção de di-butil ftalato (DBP) foi estudado pelos autores na faixa de 40 e 140 mg L ${ }^{-1}$ de CA de casca de noz (NAC) na concentração de $5 \mathrm{mg} \mathrm{L}^{-1}$ de DBP e pH 5 . O tempo necessário para estabilizar o equilíbrio foi, em todos os casos, definido pelos autores como 30 h. A capacidade de adsorção caiu de $61,36 \mathrm{mg}^{-1}$ para 32,15 $\mathrm{mg} \mathrm{g}^{-1}$, as concentrações de NAC aumentaram de $40 \mathrm{mg} \mathrm{L}^{-1}$ para $140 \mathrm{mg} \mathrm{L}^{-1}$. De acordo com os autores, a diminuição na capacidade de adsorção deveu-se ao aumento da dose de adsorvente (Fang \& Huang, 2009; Julinova \& Slavik, 2012). O último fator estudado pelos autores em seu trabalho envolveu os efeitos do pH na sorção de di-(n-butil) ftalato (PAD) no NAC. Capacidade de adsorção aumentou de $43,36 \mathrm{mg} \mathrm{g}^{-1}$ a $\mathrm{pH} 3$ para um valor máximo de 50,73 $\mathrm{mg} \mathrm{g}^{-1}$ a pH 5 . No entanto, em valores de $\mathrm{pH}$ mais elevados a capacidade de adsorção reduziu para $42,98 \mathrm{mg} \mathrm{g}^{-1}$ a $\mathrm{pH}$ 9. Isto implica que o melhor valor de pH situa-se entre 5 e 7 (a semi-vida de DBP a pH 7 foi 6,5 h). Este fato é explicado pelos autores como segue: a pH 7, o a molécula de DBP hidrolisa para ácido. Enquanto o grupo carbonila do ácido ftálico foi nucleofilico, reagiu prontamente com os íons de hidrogênio na solução e adquiriu um valor positivo ao se carregar: Isto leva a uma repulsão eletrostática intensificada entre NAC e DBP na solução. No entanto, se o pH da solução exceder 7, a superfície NAC adquire uma carga negativa, enquanto a DBP hidrolisa para produzir ânions de ftalato. Neste caso, a capacidade de adsorção do NAC deve então diminuir, devido ao fato de ter havido um aumento da resistência a pressão eletrostática entre NAC e PAD. Devido à baixa solubilidade e alta hidrofobicidade dos PAEs, o CA é um adsorvente ineficiente para removê-los nestas águas contaminadas. Sabe-se que a capacidade do CA para adsorver substâncias perigosas podem ser melhoradas com produtos químicos adequados.

\subsubsection{Modelagem das isotermas de adsorção}

Resultados dos modelos de Langmuir e Freundlinch são apresentados na Tabela 14 para isoterma de C9. Os resultados demonstram que o equilíbrio é bem descrito pelas isotermas de Freundlinch, cujos coeficientes de determinação são elevados. A diferença relativa entre $\mathrm{q}_{\mathrm{m}}$ exp (capacidade de adsorção máxima experimental) e q exp calc (capacidade de adsorção máxima calculada) pode chegar a menos de $2 \%$ : As capacidades de adsorção máxima de acordo com o modelo de Langmuir (com base na adsorção na monocamada) foram estudados, no que diz respeito a superfície do CA para as isotermas de C9, C8 e C6.

Tabela 14. Valores dos parâmetros das isotermas de adsorção para Langmuir e Freundlinch.

\begin{tabular}{|c|c|c|c|c|c|c|c|c|c|}
\hline \multirow[b]{2}{*}{ 旡 } & \multicolumn{4}{|c|}{ Langmuir } & \multicolumn{5}{|c|}{ Freundlinch } \\
\hline & $\begin{array}{c}\mathbf{q m} \exp \\
\left(\mathrm{mg} \mathrm{g}^{-1}\right)\end{array}$ & $\begin{array}{c}\mathrm{qmL} \\
\left(\mathrm{mg} \mathrm{g}^{-1}\right)\end{array}$ & $\mathbf{b}$ & $\mathbf{R}^{2}$ & $\begin{array}{c}\text { qm exp (mol } \\
\left.\mathrm{g}^{-1}\right)\end{array}$ & $\begin{array}{c}\text { qe calc } \\
\left(\mathrm{mol} \mathrm{g}^{-1}\right)\end{array}$ & $\begin{array}{c}\mathbf{k F} \\
\left(\mathrm{L} \mathrm{g}^{-1}\right)\end{array}$ & $1 / n_{F}$ & $\overline{\mathbf{R}^{2}}$ \\
\hline C9 & 19,499 & 14,555 & 0,143 & 0,649 & 19,499 & 21,414 & 0,645 & 1,458 & 0,999 \\
\hline $\mathrm{C} 8$ & 17,560 & 13,189 & 0,038 & 0,952 & 2,117 & 2,1788 & 0,183 & 0,937 & 0,959 \\
\hline C6 & 14,856 & 12,699 & 0,075 & 0,808 & 2,937 & 2,63211 & 0,278 & 0,998 & 0,858 \\
\hline
\end{tabular}

Fonte: Autores. 
A termodinâmica de adsorção foi determinada utilizando-se os coeficientes de equilíbrio termodinâmico obtidos a diferentes temperaturas e concentrações para verificar possíveis mecanismos de adsorção (Crini; Badot, 2008). Assim as características de adsorção de CA podem ser expressas em termos de parâmetros termodinâmicos tais como $\Delta \mathrm{G}$ (mudança de energia livre de Gibbs), que pode ser calculada pela Equação 3.

$$
\Delta \mathrm{G}=\mathrm{RT} \ln \mathrm{k}_{\mathrm{D}} \quad \text { (Equação 3). }
$$

Onde $\mathrm{k}_{\mathrm{D}}$ é a constante de equilíbrio termodinâmica $\left(\mathrm{L} \mathrm{g}^{-1}\right)$, $\mathrm{R}$ é a constante de gás universal $\left(8.314 \mathrm{~J}^{\mathrm{mol}}{ }^{-1} \mathrm{~K}^{-1}\right)$ e $\mathrm{T}$ é a temperatura (K). De acordo com Niwas et al. (2000), $\mathrm{k}_{\mathrm{D}}$ pode ser obtida traçando $\mathrm{q}_{\mathrm{e}} / \mathrm{C}_{\mathrm{e}}$ versus $\mathrm{q}_{\mathrm{e}}$ e extrapolando $\mathrm{q}_{\mathrm{e}}$ a zero. Assim como, pode-se obter a energia livre de Gibbs $(\Delta \mathrm{G})$ e, deste modo, permitiu determinar a energia livre molar da reação $\left(\Delta \mathrm{G}=-459,52 \mathrm{~J} \mathrm{~mol}^{-1}\right)$. Quando é negativo indica que a reação é espontânea. Este valor $(\Delta \mathrm{G})$ é usado frequentemente, indicando que o processo de adsorção é favorável, e confirmou a afinidade do adsorvente para o adsorvido (Noll et al., 1991; Piccin et al. 2011).

As constantes de Freundlich $\left(\mathrm{k}_{\mathrm{F}}\right.$ e $\left.1 / \mathrm{n}_{\mathrm{F}}\right)$ dependem da interação soluto-adsorvente. A adsorção para o modelo de Freundlich foi mais favorável em $\mathrm{C} 9$, porque o valor de $1 / \mathrm{n}_{\mathrm{F}}>1$, a adsorção é favorável; já para C8 o valor de $1 / \mathrm{n}_{\mathrm{F}}<1$, indica uma adsorção negativa. A constante de $\mathrm{n}_{\mathrm{F}}$ apresenta forte afinidade para os compostos para C9, $\mathrm{n}_{\mathrm{F}}$ foi o maior, enquanto a constante $\mathrm{k}_{\mathrm{F}}$ representa a capacidade adsorção do sólido, também foi maior para C9. Por exemplo, os maiores valores de 1/n $\mathrm{n}$ $\mathrm{k}_{\mathrm{F}}$ são para C9, assim o coeficiente de determinação $\left(\mathrm{R}^{2}\right)$, também foi o maior entre as isotermas, sendo 1,45 , 0,64 e 0,99 , respectivamente, para a interação CA e DEP.

Os resultados das isotermas de adsorção tanto do estudo de remoção de ésteres de ftalato de solução aquosa por esferas de quitosana de Chen e Chung (2006), como por esferas de quitosana impregnadas com molibdato de Chen \& Chung (2007) mostraram também que o melhor modelo para descrever as isotermas foi o de Freundlich, com altos coeficientes de determinação ( $\mathrm{R}^{2}$ : 0,989-0,997). Os autores Venkata-Mohan et al. (2007) revelaram para o estudo do equilíbrio de adsorção (DEP-CA) que o modelo que se adequou melhor na adsorção de DEP em CA foi o de Freundlich. Isto com base nos resultados em condições de teste em uma temperatura de $30^{\circ} \mathrm{C}$, a $100 \mathrm{rpm}$, com 0,1 g de CA e pH 7,0. Entretanto a comparação para adsorção de ésteres de ftalato por CA foi consistente para ambos métodos de Langmuir e Freundlich para o estudo de Adhoum \& Monser (2004).

A pequena cadeia linear de DEP ligada a um anel aromático e a estrutura molecular do CA foram favoráveis à sua adsorção, provavelmente devido à permissão de difusão e à orientação espacial sobre a superfície do material. O CA mostrouse eficiente na remoção de DEP de efluente sintético preparado em bancada. Estudos realizados por Wong et al. (2003) na adsorção de corantes ácidos (nomeadamente ácido verde 25, laranja ácido 10, laranja ácido 12, vermelho ácido 18 e vermelho ácido 73, a partir de solução aquosa) por quitosana determinaram resultados desfavoráveis, devido ao tamanho da molécula e o número de grupos funcionais presentes em cada corante foi desfavorável à adsorção em quitosano. As diferenças nas capacidades de adsorção podem ser devidas ao efeito do tamanho molecular e ao número de grupos sulfonato de cada corante. Deste modo, o tamanho da cadeia e estrutura molecular influenciam no processo de adsorção, provavelmente devido à facilidade de difusão, dissociação iônica e à orientação espacial sobre a superfície do material (Shriver et al., 2006).

\subsection{Análise termogravimétrica (ATG) do CA}

Os resultados da ATG do CA são apresentados na Figura 10 pela curva da ATG $(\mathrm{mg})$ em função da temperatura $\left({ }^{\circ} \mathrm{C}\right)$ dos dados da ATG do CA lavado e dos CA(s) após as cinéticas de adsorção com CA. Pode-se observar, pela análise térmica, que o primeiro declive de massa, entre $93^{\circ} \mathrm{C}$ e $220^{\circ} \mathrm{C}$ do $\mathrm{CA}$ das cinéticas de adsorção, o valor correspondente para a desorção 
de água (o fenômeno da fisiossorção) em CA, mesmo após fisiosorção na rampa de secagem antes da análise ATG. A decomposição do CA ocorre próximo de $600^{\circ} \mathrm{C}$. A porcentagem de resíduos foi de aproximadamente $12 \%$. Os resíduos são provenientes dos óxidos formados durante o processo de aquecimento em atmosfera oxidante (Gonçalves et al., 2007).

Observou-se uma perda massa maior entre $400^{\circ} \mathrm{C}$ e $600^{\circ} \mathrm{C}$ do CA das cinéticas de adsorção. Para o CA lavado a taxa é de $17 \%$ da massa inicial. Estes resultados também mostram que entre $500^{\circ} \mathrm{C}$ e $800^{\circ} \mathrm{C}$, as características de decomposição de compostos oxigenados, assim como relatado por Cagnon et al. (2005).

Figura 10. Comparação entre as análises Termogravimétrica (ATG) do CA saturado de DEP (mg) em função da temperatura $\left({ }^{\circ} \mathrm{C}\right)$ após as cinéticas de adsorção em CA, $\mathrm{C} 1(--) \mathrm{pH} 3,0,2 \mathrm{~g} \mathrm{CA}, 15^{\circ} \mathrm{C}$; $\mathrm{C} 2(--) \mathrm{pH} 3,0,6 \mathrm{~g} \mathrm{CA}, 15^{\circ} \mathrm{C}$; C3 (--) pH 11, 0,2 g $\mathrm{CA}, 15^{\circ} \mathrm{C}$; $\mathrm{C} 4(--) \mathrm{pH} 11,0,6 \mathrm{~g} \mathrm{CA}, 15^{\circ} \mathrm{C}$; $\mathrm{C} 5$ (--) pH 3, 0,2 g CA, $45^{\circ} \mathrm{C}$; $\mathrm{C} 6(--) \mathrm{pH} 3,0,6 \mathrm{~g} \mathrm{CA}, 45^{\circ} \mathrm{C}$; $\mathrm{C} 7(--) \mathrm{pH} 11,0,2 \mathrm{~g}$ $\mathrm{CA}, 45^{\circ} \mathrm{C}$; $\mathrm{C} 8$ (--) pH 11, 0,6 g CA, $45^{\circ} \mathrm{C}$; $\mathrm{C} 9$ (--) pH 7, 0,4 g CA, 30 $3{ }^{\circ} \mathrm{C}$; $\mathrm{C} 10$ (--) pH 7, 0,4 g CA, 30 $30^{\circ} \mathrm{C}$; $\mathrm{C} 11$ (--)pH 7, 0,4 g $\mathrm{CA}, 30^{\circ} \mathrm{C}$ e do CA lavado (--) (pré-cinética) em atmosfera de ar sintético.

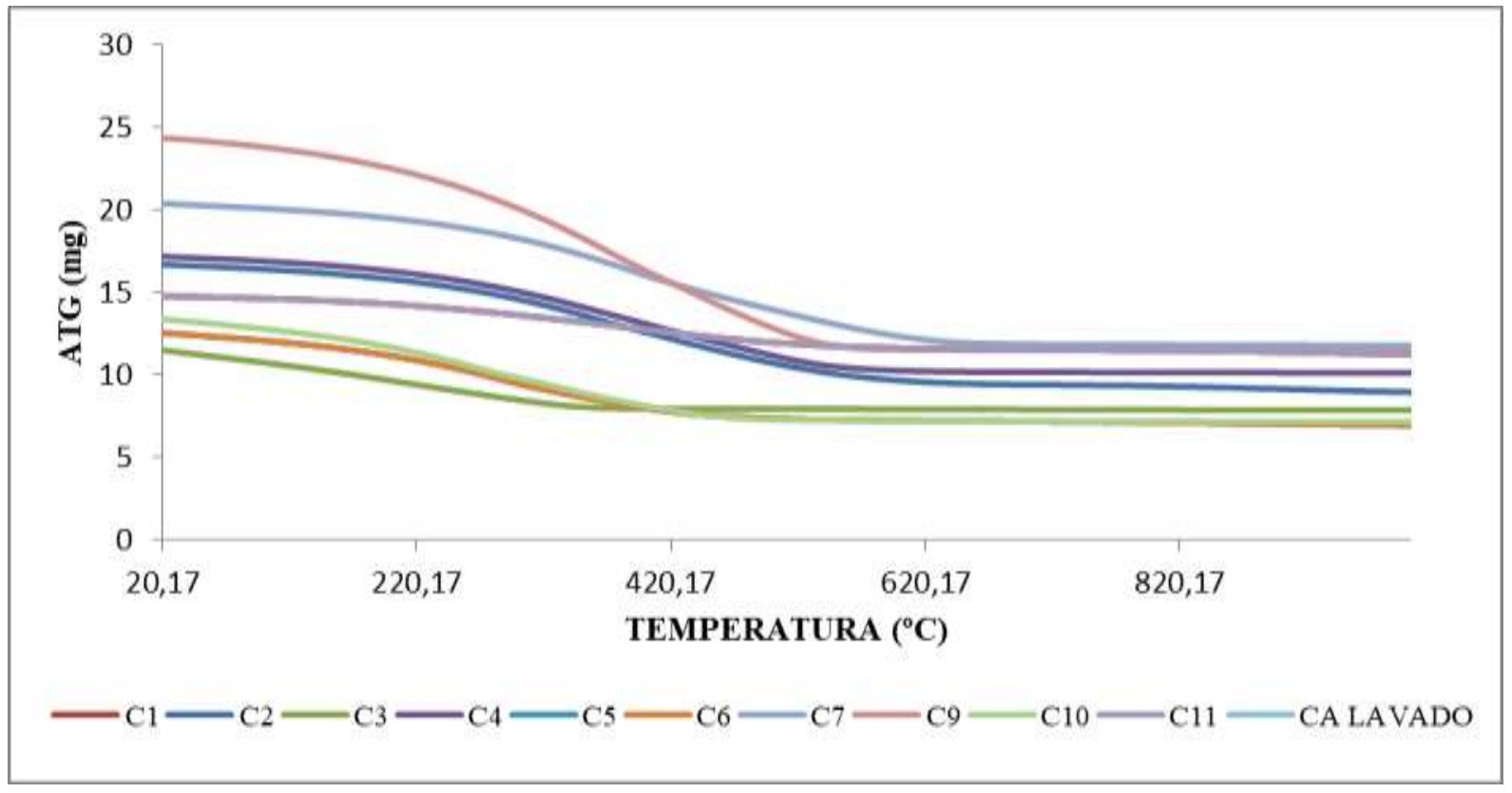

Fonte: Autores.

\subsection{Microscopia eletrônica de varredura (MEV) de CA}

As estruturas de CAs pré e pós-cinéticas de adsorção de DEP em CA foram determinadas. A atividade e a estabilidade de CA dependem da sua estrutura, e a fim de melhor compreender o comportamento de CA como catalisador no processo de adsorção, as características estruturais de CA pré e pós-cinéticas das melhores condições de tratamento foram analisadas.

As imagens de MEV do CA são apresentadas na Figura 11. Em comparação com as imagens de MEV de CA pré uso, e pós utilização é tênue. Algumas partículas sobre a superfície do CA antes do uso nos tratamentos são dificeis de encontrar nas imagens de MEV de CA utilizado. No entanto, a estrutura dos poros de CA não foi danificada, deste modo, claramente as propriedades texturais foram mantidas. Então, pode-se confirmar o que Zhang et al. (2014) disseram, que em um processo de reutilização de CA, por longo tempo não se altera, significamente, as suas propriedades texturais. 
Research, Society and Development, v. 10, n. 14, e289101421966, 2021

(CC BY 4.0) | ISSN 2525-3409 | DOI: http://dx.doi.org/10.33448/rsd-v10i14.21966

Figura 11. Imagens de MEV de CA pré cinéticas (a, b), pós cinéticas de adsorção C9 (c, d).

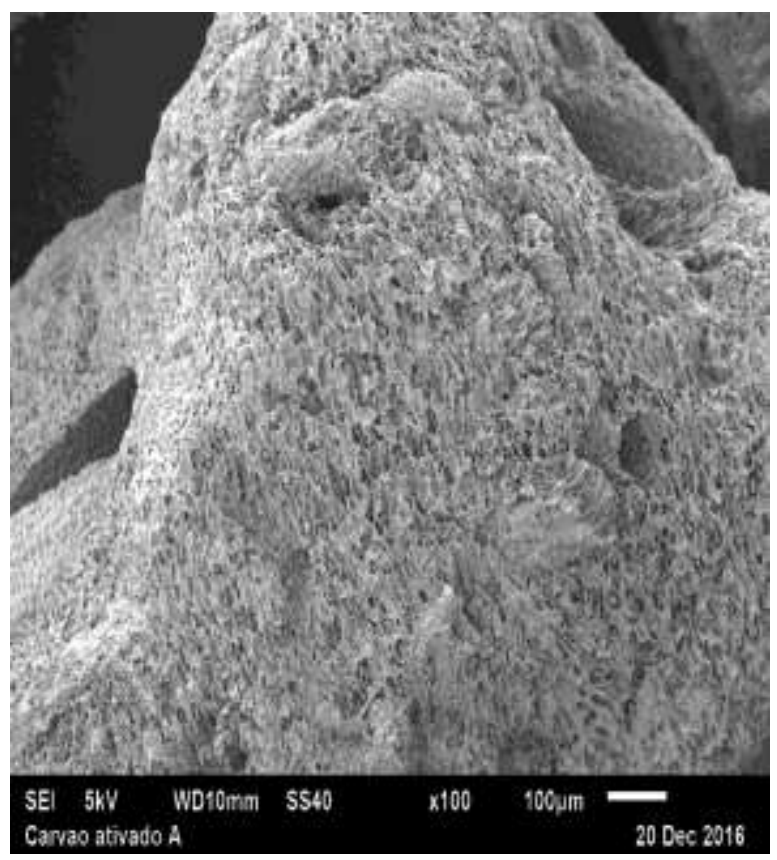

(a)

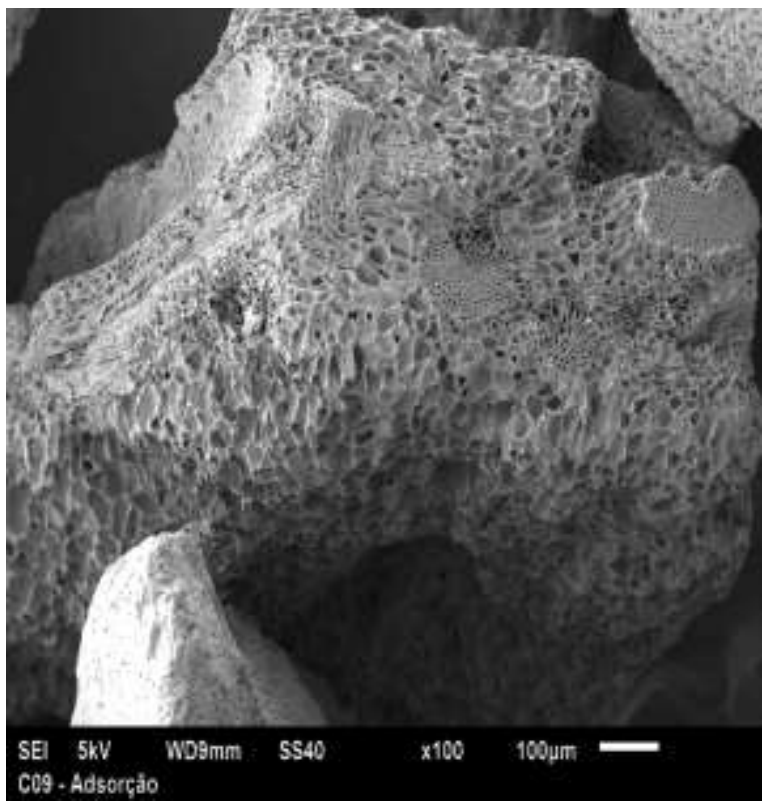

(c)

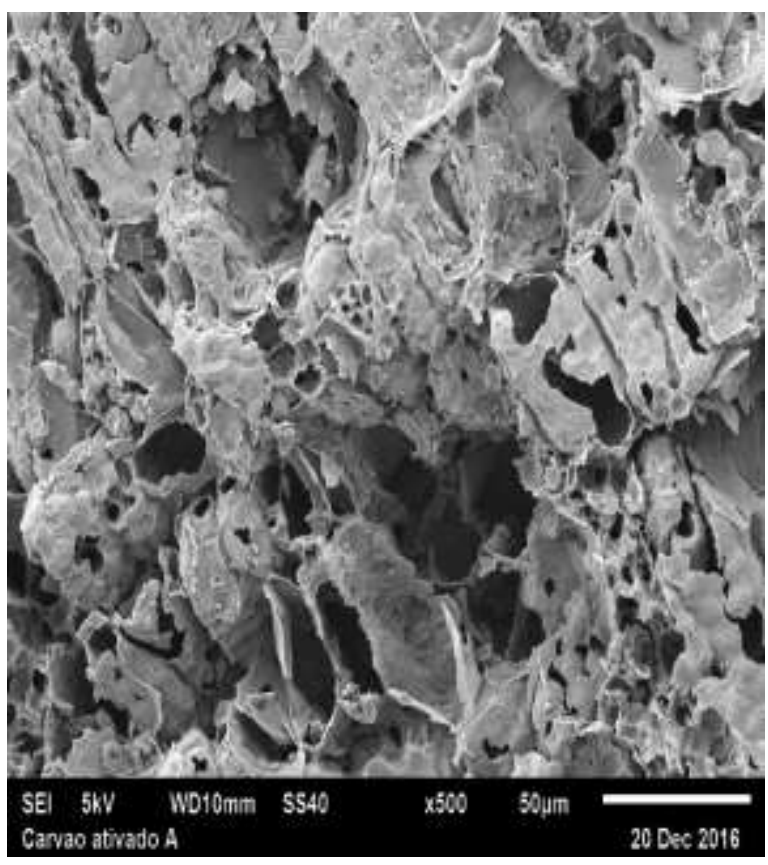

(b)

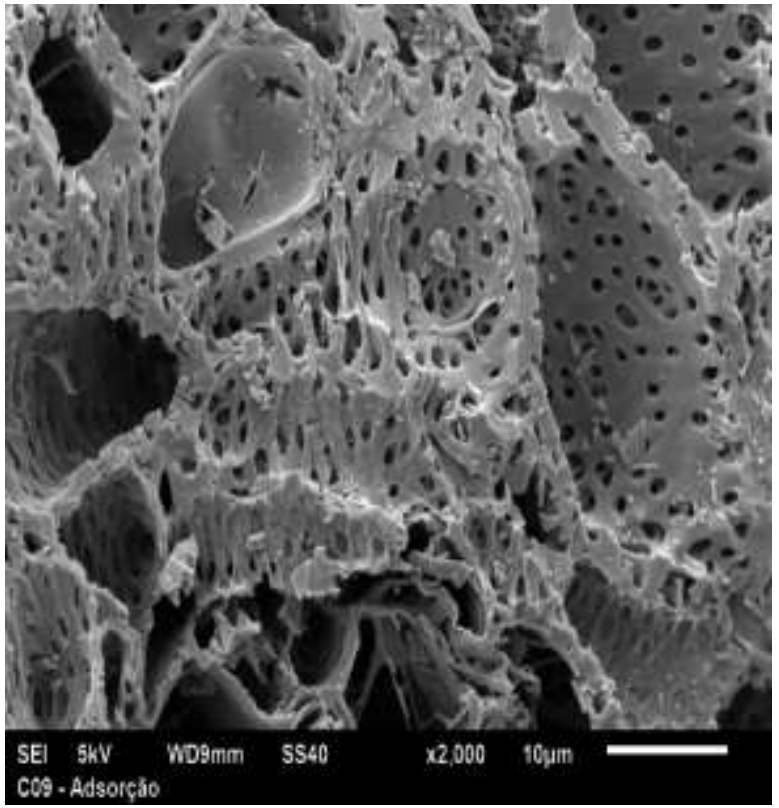

(d)

Fonte: Autores.

\section{Conclusão}

O CA obtido a partir do resíduo de agroindústria (casca de coco verde) apresentou área superficial pequena (554,228 $\left.\mathrm{m}^{2} \mathrm{~g}^{-1}\right)$, área microporosa $\left(460,0539 \mathrm{~m}^{2} \mathrm{~g}^{-1}\right)$ e volume microporoso elevados $\left(0,253081 \mathrm{~cm}^{3} \mathrm{~g}^{-1}\right)$ pelo método de BET e BJH, quando comparada com os descritos na literatura, e apresentou considerável capacidade máxima de adsorção de DEP (27,006 $\mathrm{mg} \mathrm{g}^{-1}$ ) em pH 7, com 0,4 g de CA a $30^{\circ} \mathrm{C}$ em 360 minutos). A modelagem das cinéticas de adsorção ajustou-se ao modelo de pseudo-segunda ordem, assim como, a modelagem das isotermas de equílibrio ao modelo de Freundlinch. Deste modo, confirmou-se o favorecimento do fenômeno predominante de quimiosorção. O fato do CA apresentar capacidade máxima de 
adsorção mais elevada para DEP em condição experimental de $\mathrm{pH} 7$, salvo que o pH $\mathrm{PZC}$ de $\mathrm{CA}(7,2)$, pode-se ratificar maior interação entre as cargas apresentadas pela superfície do CA (adsorvente) e a habilidade das moléculas de DEP em acessar os poros do material adsorvente com característica básica (lactonas e fenóis). Os resultados revelaram que o CA produzido a partir de resíduo de agroindústria é um potencial adsorvente para micropoluentes como DEP e de outros contaminantes em meio aquoso. Deste modo se torna uma fonte alternativa para a produção de materiais adsorventes de baixo custo e eficiente agente de tratamento por processo de adsorção de micropoluentes (substâncias prioritárias e perigosas) de efluente agroindustrial. Já que atingiu uma taxa de 83,5\% de eliminação de DEP em 360 minutos. Além disso, há possibilidade de reuso do CA, visto que suas propriedades texturais foram mantidas pós-cineticas de tratamento para eliminar DEP. Estudos posteriores poderão associar uso da adsorção acoplada aos Processos Oxidativos Avançados, a fim de otimizar a eliminação de dietil ftlato, assim como, outros poluentes orgânicos emergentes, persistentes em efluentes, mesmo após tratamento convencional.

\section{Agradecimentos}

Agradecemos ao CNPQ pelo apoio à pesquisa (Projeto Universal N. 4054962018-4), à Universidade Federal de Goiás pela infraestrutura, ao Instituto Federal de Educação, Ciência e Tecnologia de Goiás (IFG) pelo apoio financeiro/infraestrutura e ao Grupo de Estudos em Energias Renováveis e Ambiente (GEERA) pelas relevantes contribuições neste trabalho.

\section{Referências}

Adhoum, N. \& Monser, L. (2004). Removal of phthalate on modified activated carbon: application to the treatment of industrial wastewater. Sep. Purif. Tech., $38,233-239$.

Abdelmelek, S. B., Greaves, J., Ishida, K. P., Cooper, W. J. \& Song, W. (2011). Removal of pharmaceutical and personal care products from reverse osmosis retentate using advanced oxidation processes. Envir. Scien. Tech., 45, 3665-3671.

Ahmad, A.L., Loh, M. M. \& Aziz, J. A. (2007). Preparation and characterization of active carbon from oil palm wood and its evaluation on methylene blue adsorption. Dyes Pigm., 75, 263-72.

Almeida, M. C., Sá, F. P. \& Oliveira, T. F. (2020). The elimination of cancerous pollutants by an advanced oxidative processes and adsorption in monosolute solutions mixtures in water. Desalin. Water Treat., 191, 292-299.

Asheh, A. S., Banat, F. \& Aitah, L. A. (2003). Adsorption of phenol using different types of activated bentonites. Sep. Purif. Tech., 33, 1-10.

ASTM. D 5373/2008. (2008). Standard Test Methods for Instrumental Determination of Carbon, Hydrogen, and Nitrogen in Laboratory Samples of Coal and Coke. In: Annual Book of ASTM Standards, Pennsylvania.

Bajpai, S. K., Bajpai, M. \& Rai, N. (2012). Sorptive removal of ciprofloxacin hydrochloride from simulated wastewater using sawdust: kinetic study and effect of $\mathrm{pH}$. Water $S A, 38(5), 673-682$.

Barbosa, C. S., Santana, S. A. A., Bezerra, C. W. B., Silva, H. A. S. S. (2014). Remoção de compostos fenólicos de soluções aquosas utilizando carvão ativado preparado a partir do aguapé (Eichhornia crassipes): estudo cinético e de equilíbrio termodinâmico. Quím. Nova, 37(3), 447-453.

Benkedda, J., Jaubert, J.N., Barth, D., Perrin, L., Baily, M. (2000). Adsorption isotherms of m-xylene on activated carbon: measurements and correlation with different models. J. Chem. Thermodym., 32, 401-411.

Bertolini, T. C. R. \& Fungaro, D. A. Estudos de equilíbrio e modelagem cinética da adsorção do corante cristal violeta sobre zeólitas de cinzas leve e pesada de carvão. São Paulo, Brazil. Cleaner Production Initiatives and Challenges for a Sustainable World. 2011; May $18^{\text {th }}-20^{\text {th }}: 1-10$.

Boehm, H. P. (2002). Surface oxides on carbon and their analysis: a critical assessment. Carbon., 40, 145-149.

Boehm, H. P., Diehl, E., Heck, W. \& Sappok, R. (1964). Surface oxides on carbon. Angew. Chemie Intern. Ed., 3(10), 669:-67.

Cagnon, B., Py, X., Guillot, A., Joly, J. P. \& Berjoan, R. (2005). Pore modification of pitch-based activated carbon by NaOCl and air oxidation/pyrolysis cycles. Microp. Mesop. Mater., 80, 183-193.

Call, D. J., Markee, T. P., Geiger, D. L., Brooke, L. T., Vanderventer, F. A., Cox, D. A., Genisot, K. I., Robillard, K. A., Gorsuch, J. W., Parkerton, T. F., Reiley, M. C., Ankley, G. T. \& Mount, D. R. (2001). An assessment of the toxicity of phthalate esters to freshwater benthos. 1. Aqueous exposures. Environ. Toxicol. Chem. 20, 1798-1804. 
Chan, H. W., Lau, T. C., Ang, P. O., Wu, M. \& Wong, P. K. (2004). Biosorption of di(2-ethylhexyl) phthalate by sea weed biomass. App. Phycol., 16(4):263274.

Chaudhary, D. S., Vigneswaran, S., Jegatheesan, V., Ngo, H. H. \& Moon, H. (2003). Granular activated carbon (GAC) adsorption in tertiary wastewater treatment: experiments and models. Water Sci. Tech., 47(1), 113-1120.

Chen, C. Y. \& Chung, Y. C. (2007). Removal of phthalate esters from aqueous solution by molybdate impregnated chitosan beads. Environ. Engi. Sci., 24(6, 834-841.

Chen, C. Y. \& Chung, Y. C. (2006). Removal of phthalate esters from aqueous solution by chitosan bead. J. Environ. Sci. Health, Part A, 41, 235.

Crini, G. \& Badot, P. M. (2008). Application of chitosan, a natural aminopolysaccharide, for dye removal from aqueous solutions by adsorption processes using batch studies: A review of recent literature. Prog. Polym. Sci., 33(4), 399-447.

Dabrowski, A., Podkoscielny, P., Hubick, Z., Barczk, M. (2005). Adsorption of phenolic compounds by activated carbon: a critical review. Chemosp., 58(8), 1049-1070.

Den, W., Liu, H. C., Chan, S. F., Kin, K. T. \& Huang, C. (2006). Adsorption of phthalate esters with multiwalled carbon nanotubes and its applications. J. Environ. Engin. Manag., 16(4), 275-282.

Fallavena, V. L. V., Abreu, C. S. A., Inácio, T. D., Pires, M. \& Azevedo, C. M. N. (2013). Caracterização detalhada de material de referência certificado de carvão brasileiro. Quím. Nova, 36(6), 859-864.

Fang, Z. Q. \& Huang, J. (2009). Adsorption of di-n-butylphthalate onto nutshell-based activated carbon: equilibrium, kinetics and thermodynamics. Adsorp. Sci. Techn., 27(7), 685-700.

Faria, P. C. C., Orfao, J. J. M. \& Pereira, M. F. R. (2004). Adsorption of amionic and cationic dyes on activated carbons with diferente surfasse chemistries. Water Res., 38(8), 2043-2004

Fierro, V., Torne-Fernandez, V., Montane, D. \& Celzard, A. (2008). Adsorption of phenol onto activated carbons having different textural and surface properties. Microp. Mesop. Mater., 111, 276-284.

Fu, J., Chen, Z., Wang, M., Liu, S., Zhang, J., Zhang, J., Han, R. \& Xu, Q. (2015). Adsorption of methylene blue by a high-efficiency adsorbent (polydopamine microspheres): kinetics, isotherm, thermodynamics and mechanism analysis. Chem. Engin. J., 259, 53-61.

Flouret, A., de Almeida, M. C., de Oliveira, T. F., \& de Sá, F. P. (2018). Advanced treatment of phenol by $\mathrm{H}_{2} \mathrm{O}_{2} /$ UV/activated carbon coupling: influence of homogeneous and heterogeneous phase. The Canad. J. Chem. Eng., 96(9), 1979-1985.

Freitas, A. F. (2005). Estudo da Adsorção de Ácidos Carboxílicos em Diferentes Materiais Adsorventes. 113p. Dissertação (Mestrado em Ciências em Engenharia Química, Área de Concentração Engenharia Ambiental) - Instituto de Tecnologia, Departamento de Engenharia Química, Universidade Federal Rural do Rio de Janeiro (UFRRJ), Seropédica, RJ.

Gani, K. M. \& Kazmi, A. A. (2016). Phthalate contamination in aquatic environmental: a critical review of the process factors that influence their removal. Crit. Rev. Environ. Sci. Tecn., 0, 1-38.

Gonçalves, M., Guerreiro, M. C., Bianchi, M. L., Oliveira, L. C. A., Pereira, E. I. \& Dallago, R. M. (2007). Produção de carvão a partir de resíduo de ervamate para a remoção de contaminantes orgânicos de meio aquoso. Ciência e Agrotec., 31(5), 1386-1391.

Guilarduci, V. V. S., Mesquita, J. P., Martelli, P. B. \& Gorgulho, H. F. (2006). Adsorção de fenol sobre carvão ativado em meio alcalino. Quím. Nova, 29, 1226-1232.

Ho, Y. S, Wase, D. A. J. \& Forster, C. F. (1996). Kinetic studies of competitive heavy metal adsorption by sphagnum moss peat. Environ. Techn., 17, $71-77$.

Hocine, O., Boufatit, M., Khouider, A. (2004). Use of montmorillonite clays as adsorbents of hazardous pollutants. Desalin., 167, 141-145.

Ishizaki, K., Shinriki, N., Ikehata, A. \& Ueda, T. (1981). Degradation of nucleic acids with ozone. I. Degradation of nucleobase, ribonucleosides and ribonucleoside-5'-monophosphates. Chem. Pharmac. Bull., 29(3), 3601.

Julinova, M. \& Slavik, R. (2012). Removal of phthalates from aqueous solution by different adsorbents: a short review. J. Environ. Manag., 94(1), 13-24.

Juszczak, L., Fortuna, T. \& Wodnicka, K. (2002). Characteristics of cereal starch granules surface using nitrogen adsorption. J. Food Engin., 54, 103-110.

Kim, S. D., Cho, J., Vanderfford, B. J. \& Snynder, S. A. (2007). Occurance and removal of pharmaceutical and endocrine disruptors in South Koren surfasse, drinking, and waste Waters. Water Res., 41, 1013-1021.

Kumar, A., Kumar, S. \& Kumar, S. (2003).Adsoption of resorcinol and catechol on granular activated carbon: Equilibrium and Kinetics. Carbon, 41,3015-3025.

Lagergren, S. (1898). On the theory of so-called adsorption dissolved substances. Handlingar Band, 24, 1-39.

Li, A., Zhang, Q., Zhang, G., Chen, J., Fei, Z., \& Liu, F. (2002). Adsorption of phenolic compounds from aqueous solutions by a water-compatible hypercrosslinked polymeric adsorbent. Chemosp., 47(9), 981-89.

Lyubchik, S. I., Lyubchik, A. I., Galushko, O. L., Tikhonova, L. P., Vital, J., Fonseca, I. M. \& Lyubchik, S. B. (2004). Kinetics and thermodynamics of the Cr (III) adsorption on the activated carbon from co-mingled wastes. Colloids and Surfaces, 242,151-58. 
Mendez-Diaz, J. D., Prados-Joya, G., Rivera-Utrilla, J., Leyva-Ramos, R., Sanchez-Polo, M., Ferro-Garcıa, M. A. \& Medellın-Castillo, N. A. (2010). Kinetic study of the adsorption of nitroimidazole antibiotics on activated carbons in aqueous phase. J. Colloid Interf. Sci., 345, 481-90.

Moreno-Castilla, C. (2004). Adsorption of organics molecules from aqueous solutions on carbon materials. Carbon 2004:42(1):83-94.

Moreno-Castilla, C., Carrasco-Marín, F., Lopez-Ramon, M. V. \& Álvarez-Merino, M. A. (2001). Chemical and physical activation of olive-mill wastewater to produce activated carbons. Carbon, 39(9), 1415-1420.

Net, S., Sempéré, R., Delmont, A.; Paluselli, A. \& Ouddane, B. (2015). Occurrence, fate, behavior and ecotoxicological state of phthalates in different environmental matrices. Environ. Sci. Techn., 1-17.

Niwas, R., Gupta, U., Khan, A. A., Varshney, K. G. (2000). The adsorption of phosphamidon on the surface of styrene supported zirconium (IV) tungstophophate: a thermodynamic study. Colloids and Surf. A: Physicoch. Engin. Aspects, 164, 115-119.

Noll, K. E., Gounaris, V. \& Hou, W. Adsorption technology for air and water pollution control. Lewis Publishers, Inc., Michigan 1992:1.

Oickle, A. M., Goertzen, S. L., Hopper, K. R., Abdalla, Y. O. \& Andreas, H. A. (2010). Standardization of the Boehm titration: Part II. Method of agitation, effect of filtering and dilute titrant. Carbon, 48(12), 3313-3322.

Oliveira, T.F. (2011a). Etude d'un procédé de depollution basé sur le couplage ozone/charbon actif pour l'elimination des phthalates em phase aqueuse. 209p. Tese (Doutorado em Engenharia Química) - Universidade de Orléans, Orléans.

Oliveira, T. F., Chedeville, O., Fauduet, H. \& Cagnon, B. (2011b). Use of ozone/actived carbon coupling to remove diethyl phthalate from water: influence of activated carbon textural and chemical properties. Desalin., 276, 359-365.

Oliveira, T. F., Chedeville, O., Cagnon, B. \& Fauduet, H. (2011c). Degradation kinetics of DEP in water by ozone/activated carbon process: influence of pH Desalin. Water Treatm., 269, 271-275.

Piccin, J. S., Dotto, G. L. \& Pinto, L. A. A. (2011). Adsorption isotherms and thermochemical data of FD\&C Red n 40 binding by Chitosan. Braz. J. Chem. Engin., 28(2), 295-304.

Radovic, I. R., Moreno-Castilla, C. \& Rivera-Utrilla, J. (2001). Carbon materials as adsorbents in aqueous solution. J. Chem. Phys. Carbon, 27, 227-406.

Ramos, P. H., Guerreiro, M. C., Resende, E. C. \& Gonçalves, M. (2009). Produção e caracterização de carvão ativado produzido a partir do defeito preto, verde, ardido (PVA) do café. Quím. Nova, 32(5), 1139-1143.

Rocha, W. D., Luz, J. A. M., Lena, J. C. \& Romero, O. B. (2006). Adsorção de cobre por carvões ativados de endocarpo de noz macadâmia e de semente de goiaba. Rev. Esc. de Minas, 59(4), 409.

Rodrigues, M. I. \& Iemma, A. F. (2009). Planejamento de experimentos e otimização de processos. 2 ed. Revisada e ampliada. Campinas, SP: Casa do Espírito Amigo Fraternidade Fé e Amor, 358p.

Salim, C. J., Liu, H. \& Kennedy, J. F. (2010). Comparative study of the adsorption on chitosan beads of phthalate esters and their degradation products. Carboh. Polym., 81, 640-44.

Santana, M. F. S., Katekawa, M. E., Tannous, K, Lima, A. K. V. O. \& Gasparetto, C. A. (2012). Área superficial e porosidade da fibra alimentar do albedo de laranja. Rev. Bras. Prod. Agroind., 14(3), 261-273.

Silverstein, R. M., Webster, F. X., Kiemle, D. J. G. C. \& Morrill, T. C. (2007). Identificação Espectrométrica de compostos orgânicos. $7^{a}$ ed., Rio de Janeiro: LTC.

Shriver, D. F., Atkins, P. W., Overton, T. L., Rourke, J. P., Weller, M. T. \& Armstrong, F. A. (2006). Inorganic chemistry, 4 ed. United Kingdom: Oxford University Press.

TRUSPEC CHN/CHNS. (2007). Carbon/Hydrogen/Nitrogen/Sulfur/ Oxygen Determinators, Instruction Manual, USA, 7, 2-14.

Tsang, D. C. W., Hu, J., Liu, M. Y., Zhang, W., Lai, K. C. K. \& Lo, I. M. C. (2007). Activated carbon produced from waste wood pallets: adsorption of three classes of dyes. Water, Air, Soil Pollut., 184, 141-155.

Venkata-Mohan, S., Shailaja, S., Krishna, M. R. \& Sarma, P. N. (2007). Adsorptive removal of phthalate ester (diethyl phthalate) from aqueous phase by activated carbon: a kinect study. J Hazard Mater., 146, 278-282.

Wang, F. F. ; Yao, J J., Sun, K. K. \& Xing, B. B. (2010). Adsorption of dialkyl phthalate esters on carbon nanotubes. Environ. Sci. Tecn., 44(18), 6985-6991.

Weber, W. J. \& Morris, J. C. (1963). Kinetics of adsorption on carbon from solution. J. Sanitary Engin., Div. ASCE, 89, 31-60.

Wigmans, T. (1989). Industrial aspects of products and use os activated carbons. Carbon, 27(1), 13-22.

Witthunn, B., Klauth, P., Klumpp, E., Narres, H. D. \& Martinius, H. (2005) Sorption and biodegradation of 2,4-dichlorophenol in the presence of organoclays. App. Clay Sci., 28, 55-66.

Wong, Y. C., Szeto, Y. S., Cheung, W. H. \& Mckay, G. (2003). Equilibrium studies for acid dye adsorption onto chitosan. Langmuir, 19, 7888-7894.

Xu, Z., Zhang, W., Pan, B., Lv, L. \& Jiang, Z. (2011). Treatment of aqueous diethyl phthalate by adsorption using a functional polymer resin. Environ. Techn., 32(2), 145-153. 
Research, Society and Development, v. 10, n. 14, e289101421966, 2021

(CC BY 4.0) | ISSN 2525-3409 | DOI: http://dx.doi.org/10.33448/rsd-v10i14.21966

Xu, Z., Zhang, W., Pan, B., Hong, C., Lv, L., Zhang, Q., Pan, B. \& Zhang, Q. (2008). Application of the Polanyi potential theory to phthalates adsorption from aqueous solution with hyper-cross-linked polymer resins. J. Colloid Inter. Sci., 319, 392-397.

Zhang, S., Han, Y., Wang, L., Chen, Y. \& Zhang, P. (2014). Treatment of hypersaline industrial wastewater from salicylaldehyde production by heterogeneous catalytic wet peroxide oxidation on commercial activated carbono. Chem. Engin. J., 252, 141-149.

Zhang, W., Xu, Z., Pan, B., Hong, C., Jia, K.,Jiang, P. \& Zhang, Q. (2008). Equilibrium and heat of adsorption of diethyl phthalate on heterogeneous adsorbents. J. Coloid Inter. Sc., 325, 41-47. 